\title{
ADOPTION TIME OF A MATURING DISRUPTIVE TECHNOLOGY IN A DUOPOLY MARKET
}

\author{
LiAnJiA Suni AND Jun Lin*
}

\begin{abstract}
New disruptive technologies invalidate the traditional competition dimension in continuous innovation and reconstruct the competitive landscape. These technologies leave a management gap in the adoption of new technologies by competing companies. Accordingly, this research establishes a duopoly game model based on horizontal and vertical differentiations for technology competition problems with asymmetric features. Competition between firms and technologies are investigated simultaneously. We find that a profit increase from new technologies is typically eliminated by the increased technology competition. Thus, firms with competitive advantages in the old market might be late in adopting new technologies, and the competition will further delay the adoption process. We then introduce a preemption strategy for adopting disruptive technologies, and test it in both current established competition and threat competition from the entrants. Results show that leading companies might hesitate in deterring new entrants for fear of losing the leadership in the current competition. Finally, we provide a time strategy that can help the market leader maintain a leadership position with minimal losses. Our research has contributed to the studies of both the interpretation of the "innovator's dilemma" and the direction of technology adoption research under multi-dimensional technologies and multiple competitors.
\end{abstract}

Mathematics Subject Classification. 91A55.

Received February 23, 2021. Accepted November 25, 2021.

\section{INTRODUCTION}

Technological changes are critically important to firms because they can render the intellectual capital of incumbents obsolete and create exploding demand in the market [22]. The adoption of the new disruptive technology has quickly become a hot topic in the business world in the 21st century since the emergence of disruptive innovations [60]. Especially, now that we have all disruptive technologies suddenly converging - IoT, robotics, self-driving cars, AI, 3D printers, VR and blockchains. A study in 2018 from Accenture [1] analysed more than 3600 companies in 82 countries and found that 63 percent of companies facing high levels of disruption and 44 percent with susceptibility to future disruption. However, only $30 \%$ companies might survive in the disruptive technologies transformation as shown by the Boston Consulting Group's latest report [12].

Over the past 20 years, we have known much about how to identify the shifts of disruption and the dangers they pose to existing businesses [50]. Nevertheless, the timing of disruptive technological change remain unsolved

Keywords. Disruptive technologies, asymmetric competition, innovator's dilemma, game theory.

School of Management, Xi'an Jiaotong University, No. 28, Xianning West Road, Xi'an, Shaanxi 710049, P.R. China.

*Corresponding author: ljun@mail.xjtu.edu.cn 
and we have poor tools to know the time when such a transition will happen [3]. The timing of disruption is a delicate equation between premature adoption when the technology is immature and loss of competitive advantage when it is adopted too late. Firms can be too late and miss the revolution, Blockbuster ignored the change from video rentals to streaming and failed; they can also be too early and exhausting the resources, think of those web companies that collapsed at the beginning of the 21st century.

There are many factors affecting the adoption of disruptive technologies: Firstly, the disruptive technology has raised entrepreneurs' fears on asymmetric competition between technologies. Traditional research on firstmover advantage [42] is not fully applicable, as it can lead to wrong technology paths [14]. Firms need to take a "wait and see" approach at the early stage of the disruptive technology [27]; Secondly, the disruptive technology has greatly expanded our understanding of competitive dynamics. Competition exists not only between firms but also between technologies. The coupling effect of the multiple competitions present significant analytical complexity $[40,46,68]$. The traditional competitive advantage can hardly be sustainable $[2,42,58]$, as the interaction mechanism between inter-technology and inter-firm competition is unclear [18]; Finally, the study of disruptive technologies highlights the asymmetry of competition $[15,35]$. The reaction to the disruptive technology could be in different ways between the established competitors and the entrants [63]. The market leader needs to consider a combination of pressure from the existing competitors and the threat of new entrants [52], or they may fail in some crucial way like the "innovator's dilemma" [62]. In this case, complete treatment of adoption timing strategies needs to incorporate the measurement of the technological boundaries in the presence of technological competition, competitive interactions among firms in the marketplace, and the threat of the entrants. We address some fundamental questions pertinent in such environments:

(1) What's the impact of inter-technology competition on the adoption time of the maturing disruptive technology?

(2) What roles do firms' technology decisions play in relieving or exacerbating the pressures of market competition?

(3) How should companies adjust their disruptive technology adoption strategies in the face of the "innovator's dilemma"?

To answer these questions, we develop a model on the basis of horizonal and vertical differentiation $[47,48]$. The traditional one-dimensional model is then extended. To differentiate our findings from previous "timing" research, we assume that the new technology is no longer "better" than the old technology at the very beginning; rather, it has a mature process, and these technologies will compete in the process. For the firms' competition, specially, we differentiate two types of competitors, namely, the incumbent competitor(s) in the old market and the entrant competitor(s) entering the market with only the new technology. With this conjoint framework we find that there are two key factors that affect the delay in adoption of disruptive technologies for market leaders: the first one is that the technological competition will reduce market leaders' alertness to the competitors' entry; and the other one is that the increased firm competition eliminates the profits facilitated by the new disruptive technology. Affected by these factors, it is easier for market leaders to fall into the risk of losing their future market leadership in the process of adopting disruptive technologies. And we find that when considering both incumbent competitors and the threat of entrants, market leaders will encounter a kind of decision-making dilemma when adopting disruptive technologies, that is to defend the underlying threat would lose to the incumbent competitor.

At last, we provide different pre-emption strategies for market leaders to face incumbent competitors and entry threats, which can help the market leaders protect their leadership with minimal losses by investing in advance. This study contributes to the literature by investigating how asymmetric firms' competition and asymmetric technological competition impact market leader's adoption timing decisions of the disruptive technology. In management practice, our results show that appropriate early investment can help market leaders to get out of this short-run profit maximization trap. More precisely, market leaders have an advantage over the incumbent competitors in this kind of pre-emption strategy and this pre-emption strategy would shift to an earlier date affected by the entry threat. Compared with managerial failures and other reasons cited in the disruptive innovation 
literature, this operational reality provides another possible explanation for the "innovator's dilemma" from a rational perspective.

\section{Literature REVIEW}

Three primary streams of research are related to our work, namely, the marketing and economic literature on technology diffusion, the operation literature about the time to market tradeoffs under competition, and the strategic literature on firm failures. Herein, we briefly review these broad areas with further references to the relevant works included throughout the remainder of this paper.

\subsection{Literature on technology diffusion and adoption}

Our model explains the dynamics of technology substitution. Foster [26] posited the theory of S-curves and suggested that technologies evolve along successive S-curves. The latter has become the canonical representations of the technology's life cycle $[37,64]$. Traditional researches mainly focus on one performance dimension (e.g., high or low) to consider the smooth substitution between two technologies [32,55]. For technology adoption, the main issues that researchers pay attention to are flexibility, quick response, ease of operation, enhanced satisfaction and risk [34]. For example, Bhaskaran and Ramachandran [10] studied the dynamic technology selection problem in the presence of a strategic competitor while considering the development flexibility. Kirshner et al. [43] analyzed the optimal upgrade strategy by considering the risk of product failure and the influence of brand commitment. However, the literature excludes the very question of whether or not two technologies compete [18]. The emergence of technology competition has been the hot topic of formal economic theory since the pioneer work of Christensen [17]. More details can be found in the systematic literature review given by Petzold et al. [57]. A disruptive technology introduces a new performance dimension and suffers from inferior performance on the key dimension [14]. Most studies defined disruptive technologies based on its evolutionary process $[7,31]$. Then many researchers pay attention on the methods to help the managers identify the emergence of disruptive technologies and the associated risks [39,53]. Such as, Bildosola et al. [11] studied the adoption of new emerging technologies while using the case of big data, they considered the way to understand and identify the potential technology. Studies in this vein focus on whether substitution will occur, but they fail to specify how to cope with it. Timing is not a factor because no first-mover advantages exist, but firms gather information to reduce the chance of launching an unprofitable innovation and modify their decisions because of potential competition [49,61]. However, our case is precisely the opposite, that is, profitability resulting from next-generation launches is partly known, and timing is critical due to the possible existence of firstmover advantages. As Chen et al. [15] pointed that capturing the timing of technology adoption is just as important as exploring whether or under what circumstances the technology could become disruptive. In this way, our research extends the current studies to deal with the timing problem of the new disruptive technology. We establish a technology competition model with multi-dimensional attributes, and consider the interaction mechanism between inter-firm competition and inter-technology competition, so as to provide a key theoretical basis for the adoption of disruptive technologies.

\subsection{Literature on time to market tradeoffs}

Our work aims to deal with the timing problem of the disruptive technology. Previous works on timing market operations are also relevant to our work. Traditional studies generally recommend that new technologies replace old ones as soon as possible [56]. Recent research about cannibalization showed that the optimal timing can be later $[16,67]$. Many studies analyze the timing problem from the perspective of monopoly. Jiang et al. [41] established a multigeneration diffusion modeling framework and found that the new generation should be released after the older one has reached full market penetration. While other explanations focused on the supplyside interactions between firms. Anderson and Sunny Yang [6] studied the competitive investment problem and found that the firms would act in unison but not as leader-follower under some condition. Similarly, Wu and Lai [66] studied the time-to-market strategy under a multistage duopoly and proved that a simultaneous launching 
strategy can be optimal in a two-stage game. However, when considering the adoption time of the disruptive technology, competition exists not only between companies but also between technologies. More than that, technology licensing is also an important factor to consider in the adoption of new technologies. Growth of technology drives higher licensing rates [8], and the sale of new technology through licensing can improve the efficiency of the innovative process [5]. Wu [65] proved that licensing can be an effective method to mitigate the intensity of competition. In this way, there is a lack of research on the interaction mechanism between asymmetric technological competition and asymmetric company competition while considering the effect of technology licensing. We have filled the research gap in this area. Our model, similar to that of Jain and Ramdas [38], incorporates the effects of improvements in underlying technologies on the product introduction decision of a firm. However, Jain and Ramdas [38] focused on the product definition problem. We formulate the model in terms of profit flows rather than unit sales, prices, and costs, and analyze the diffusion effects in the relationships among profit flows over time and across generations. Recent studies have suggested that traditional competitive advantage can hardly be sustainable [23,24]. we use theoretical analysis to help explain the limitations that traditional profit-maximizing strategies play in the process of adopting disruptive technologies.

\subsection{Literature on maintaining market leadership}

Maintaining leadership under competition is another important factor in our research. Early studies favored the industry incumbents over entrants as the reason of homogeneous structures [45]. However, the recent strategy literature has taken the failure of firms in face of disruptive technological change as a hot topic and debate of intense research $[17,18]$. Early explanations are those like lack of resource allocation, failure of strategic management and risk aversion, that behave as barriers for the incumbent firms to adopt the disruptive technology. Huang and Sošić [35] studied various competition types between technologies and gave a condition that the incumbents adopt disruptive technologies at the same time with the entrants, companies may fail if they identify the conditions incorrect. Swinney et al. [62] considered an endogenous leadership game with different objectives of start-ups and the established firms, the start-up will invest early when the demand uncertainty is high. Other researches have indicated that entrants may adjust their strategy between competition and cooperation $[7,51]$. In spite of this, we still have little understanding about how disruptive technology affects competition and how to cope with loss of leadership position [33,70]. Merely discussing incumbents and new entrants cannot shape the condition of "innovator's dilemma". We consider a mixed duopoly model consisting of two distinct competitors, namely, the incumbent competitor(s) in the old market and the entrant competitor(s) entering the market with only the new technology. Similar models were frequently referred in strategic research as the asymmetry of competition. The intra-industry heterogeneity has attracted a large number of strategic researchers $[13,63,69]$. Zhu and $\mathrm{Wu}$ [71] modeled two asymmetric retailers and showed that the leading retailer may choose the older products due to the response behaviors of the follower. Two key differences, such as the comprehensive analysis of symmetric and asymmetric competition, and the comparation of different purpose of the incumbent in the adoption time of the new disruptive technologies, were not considered. When dealing with disruptive technologies and entry threats, many studies have suggested to preempt to deter the entry [21,59]. Huberts et al. [36] examined a framework with incumbent and entrant to show that entry deterrence is achieved through timing. Many empirical studies of dynamic competition use the "Red Queen competition" to express similar views [29]. In this way, our model compares the changes in the technological boundaries faced by market leaders in the case of corporate profit maximization and competition entry. By comparing the different adoption motivations of companies, we provide a reliable analysis basis for companies facing the "innovator's dilemma". To the best of our knowledge, none of these studies analyzed a mixed duopoly consisting of two different kinds of competitors together, nor considered the new competitive technology timing as an issue.

At last, we summarize the most relevant studies from the brief review of the aforementioned literature to distinguish our research in Table 1. 
TABLE 1. Summary of the most related studies to this paper.

\begin{tabular}{|c|c|c|c|c|c|c|c|}
\hline \multirow{2}{*}{$\begin{array}{l}\text { Author } \\
\text { (year) }\end{array}$} & \multicolumn{2}{|c|}{ Quality dimension } & \multicolumn{2}{|c|}{ Competitive setting } & \multicolumn{2}{|c|}{ Considerations } & \multirow{2}{*}{$\begin{array}{l}\text { Innovator's } \\
\text { dilemma }\end{array}$} \\
\hline & Single & Multiple & Symmetric & Asymmetric & Profitability & Market leader & \\
\hline $\begin{array}{l}\text { Huang and } \\
\text { Sošić [35] }\end{array}$ & $\circ$ & $\bullet$ & $\circ$ & $\bullet$ & $\bullet$ & $\circ$ & $\circ$ \\
\hline $\begin{array}{l}\text { Swinney et al. } \\
{[62]}\end{array}$ & $\bullet$ & $\circ$ & $\circ$ & $\bullet$ & $\bullet$ & $\circ$ & $\bullet$ \\
\hline $\begin{array}{l}\text { Bhaskaran and } \\
\text { Ramachandran } \\
\text { [10] }\end{array}$ & $\bullet$ & $\circ$ & $\bullet$ & $\circ$ & $\bullet$ & $\circ$ & $\circ$ \\
\hline $\begin{array}{l}\text { Chen and } \\
\text { Turut [14] }\end{array}$ & $\circ$ & $\bullet$ & $\circ$ & $\bullet$ & $\bullet$ & $\circ$ & $\bullet$ \\
\hline $\begin{array}{l}\text { Anderson and } \\
\text { Sunny Yang [6] }\end{array}$ & $\bullet$ & $\circ$ & $\bullet$ & $\circ$ & $\bullet$ & $\circ$ & $\circ$ \\
\hline Wu and Lai [66] & $\bullet$ & $\circ$ & $\circ$ & - & - & $\circ$ & $\circ$ \\
\hline $\begin{array}{l}\text { Huberts et al. } \\
{[36]}\end{array}$ & $\bullet$ & $\circ$ & $\circ$ & $\bullet$ & $\circ$ & $\bullet$ & $\circ$ \\
\hline This paper & $\circ$ & - & - & - & - & - & - \\
\hline
\end{tabular}

\section{MODEL SET UP}

\subsection{The assumptions}

Two types of technology $(j \in[1,2])$ exist in the market: one is existing technology $(j=e)$, such as an optical camera; and the other is new disruptive technology $(j=n)$, such as the first digital camera. Consumers are continuously (and uniformly) distributed over the unit length segment, and each of them demands one product at most. $U$ is the consumer demand for the product or the reservation utility regardless of the technology. A consumer's position $x$ on the line is the ideal point. Moreover, any distance generates a mismatch cost, which is affected by the position and unit fit cost.

A technology is assumed to have two different performance dimensions. In addition, the improvement of one attribute can only be accomplished at the expense of another owing to the multi-objective nature of new technology development $[25,54]$. According to the model developed by Gabszewicz and Thisse [28], we apply the two dimensions to Hoteling model. First, location $b_{j}$ is the first dimension in which the disruptive technology performs poorly. The two technologies are located outside of the market but on the same side for Firm $i$. The existing technology is closer to all consumers than the disruptive technology. Thus, consumers will incur minor cost to obtain the traditional technology and gain higher utility than the disruptive technology $\left(b_{j}\right.$ has the same effect as $b^{*}$ in the vertical differentiation model as shown in Fig. 1). Second, unit fit cost $K_{j}$ is the second dimension in which the disruptive technology performs well. Customers incur a specific unit fit cost $K_{j}$ to use a given product on the basis of technology $j$ and $K_{n}<K_{e}$. Thus, the average mismatching cost of the disruptive technology is low, and consumers have high utility.

We then model the competitive interaction between two profit-maximizing firms $(i \in[1,2])$. We consider a case in which two profit-maximizing Firms $i$ enter a market with a competing product with a finite life cycle $T$. As commonplace in the literature on product differentiation, we assume that two firms are located at the ends of a Hoteling line and share a measure of consumers as shown in Figure 2. The engineered product is sold in discrete units, and two types of technology can be applied to the product to improve its performance. We assume that the cost of Firm $i$ for producing a unit product on the basis of technology $j$ is $c_{i j}$. We assume that Firm 1 has more advantages than Firm 2 in the old market (technology $e$ ), which means that the unit cost 


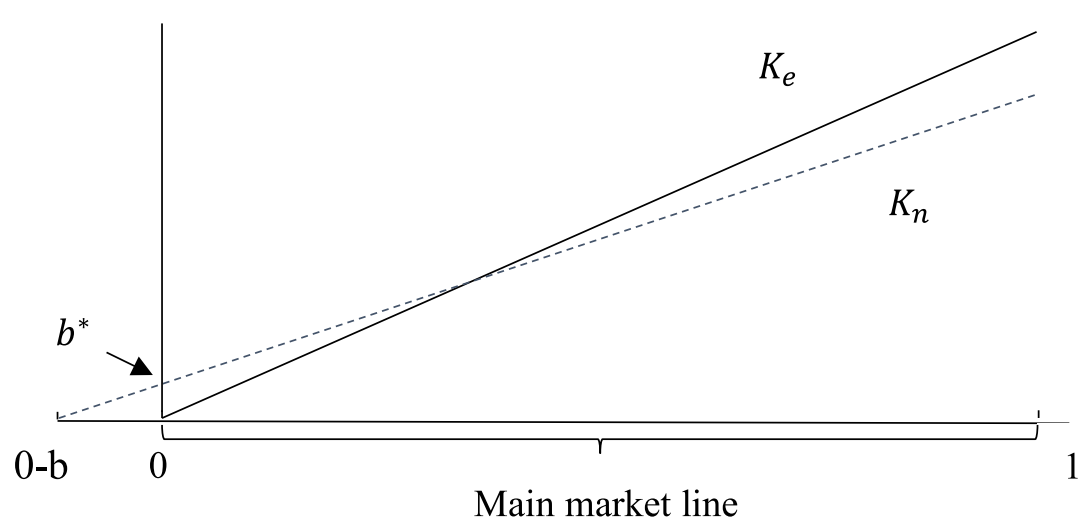

FiguRE 1. Technology performance dimension.

\section{Firm 1}

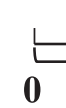

(Main market line)
Firm 2

FiguRE 2. Firm competition for market share.

$c_{1 e}<c_{2 e}$. More precisely, we assume that $c_{1 e}=c_{e}$, and $c_{2 e}=c_{e}+y$. There is no difference for the disruptive technology and the cost is $c_{n}$.

The utility of consumer buying a product from Firm 1 with technology $j$ at position $x$ is $U-K_{j}\left(x+b_{j}\right)-p_{1}$ and that from Firm 2 is $U-K_{j}\left(1-x+b_{j}\right)-p_{2}$. For simplicity, we assume that the distance of the existing technology is $b_{e}=0$ and that the distance of the disruptive technology is $b_{n}=b(t)$. Given the nature of growth technology, the distance may mature over time in the shortage dimension of its performance [14]. The exogenous technological advances are assumed to determine the performance of the new disruptive technology: firms cannot accelerate the rate, and the increment in product performance is linear $b(t)=b-k t>0$. This linear function of product performance is based on empirical studies that demonstrated the following: the speed of product performance improvement can be represented by Cobb-Douglas model [19,30] (Tab. 2).

\subsection{The framework of analysis}

We characterize the introduction of the product as a multistage game with observed actions. Herein, each firm knows the actions of other firms in past stages, but all firms move simultaneously within each stage [44]. At now or $t=0$, both firms are using the existing technology because it is the best one. We start our analysis by assuming that firms consider the timing decision of new technology adoption until the new competing technology is sufficiently "profitable". In other words, the incumbents will seek the equilibrium outcomes of maximizing the profits of two generations. Such attitude may be the conventional wisdom of most firms.

For the diffusion of the new technology, the basic channel is patent licensing. We different two cases: in Section 4, we assume that the disruptive technology is licensed by the incumbent Firm 1 (or the competitor Firm 2), and the firm will monopolize the disruptive technology. In Section 5, the disruptive technology is licensed by other third-party organizations (e.g., colleges or research institutes), and the firms would compete in the adoption game of the disruptive technology.

We then extend our model in Section 6 by assuming that market leaders will preempt the adoption of new technologies to protect their position. We compare the different effects of symmetric and asymmetric competition on the preemption strategy adoption by the market leaders, and analyze the generation mechanism of the 
TABLE 2. Notations.

\begin{tabular}{ll}
\hline \hline Symbol & Description \\
\hline$i$ & $i=1$ represents the incumbent, $i=2$ represents competitor \\
$j$ & $j=e$ represents the existing technology, $j=n$ represent the disruptive technology \\
$U$ & Reservation utility of consumers \\
$b_{j}$ & Quality dimension that disruptive technology performs poor \\
$K_{j}$ & Quality dimension that disruptive technology performs better \\
$c_{i j}$ & Unit product cost of Firm $i$ based on technology $j$ \\
$T$ & Life circle of the disruptive technology \\
$x$ & Ideal position of the certain consumer \\
$p$ & Price of the product \\
$k$ & Growth rate of the disruptive technology \\
$t$ & Current time \\
$W_{i}^{j j}$ & The one period profit of Firm $i$ the first $j$ is the technology used by Firm 1, and second by Firm 2 \\
TW & Total profits \\
$K$ & Licensing fee \\
$f$ & First adopter \\
$l$ & Latter adopter \\
$T i m$ & Monopoly adoption time of Firm $i, m=f$ or $l$ \\
$T_{i}^{m}$ & Competition adoption time of Firm $i$ \\
$T i$ & Preemption adoption time of Firm $i$ \\
$T^{\#}$ & Optimal adoption time of society \\
$T^{*}$ & Optimal adoption time of the market leader \\
\hline
\end{tabular}

"innovator's dilemma" and related solutions from the relevant differences. On this basis, we have provided some inspirations for relevant real-world management practices, and a possible explanation for the research debate in disruptive technology.

In Section 7, we test our method with a practical case, and we conclude our findings in Section 8.

\section{BASIC COMPETITION UNDER TECHNOLOGICAL MONOPOLY}

First, we consider the situation in which a single company monopolizes new technologies. A monopoly enterprise can be the one that have advantages in old technology (Firm 1) because they have resources and related knowledge to invest in the research and development of new technologies. It can also be the disadvantage one in the old market (Firm 2) or even newly entered enterprises because they have extra incentives to develop new technologies and gain a competitive advantage in new markets.

\subsection{Firm 1 monopolizes the new technology}

As shown in Figure 3, Segment 1 is the competition of the firms in the original market, and Segment 2 is the competition after the adoption of a new technology by Firm 1. Firm 1 comprehensively balances the profits obtained in the periods of Segments 1 and 2 to determine the optimal commercialization timing for the conversion of the old to new technology.

We now define a firm's demand functions. We must determine the marginal consumers, that is, the consumers are indifferent between buying from either of the two firms. Consider the marginal consumer situated in the market segment: $x \in[0,1]$. Given that the delivered prices at $x$ are equal (Fig. 2), the demand functions can be obtained as follows:

In Segment 1:

$$
K_{e} x+p_{1}=K_{e}(1-x)+p_{2} .
$$




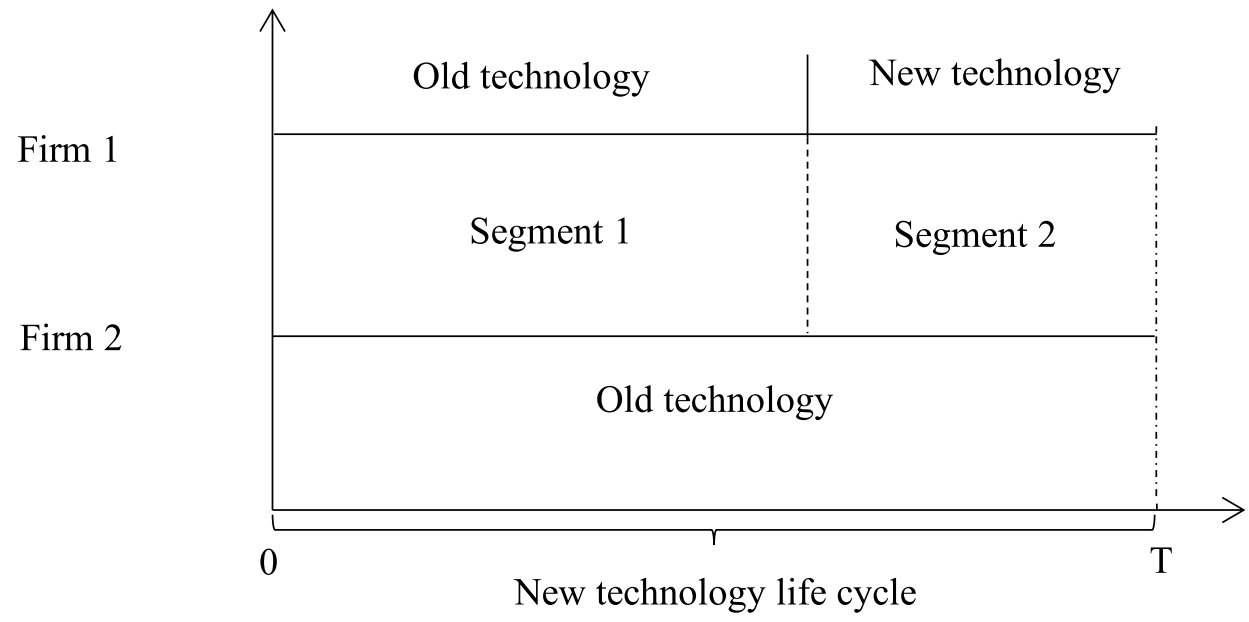

FiguRE 3. Example that Firm 1 monopolizes new technology.

In Segment 2:

$$
K_{n}(x+b(t))+p_{1}=K_{e}(1-x)+p_{2} .
$$

Through the functions above, we can obtain the demand function $x^{*}$ for Firm 1 and $\left(1-x^{*}\right)$ for Firm 2 . Under each segment, the firm has a Bertrand duopoly game on the price to maximize their profit.

$$
\begin{aligned}
& W 1_{j}=\max \left(p_{1}-c_{1 j}\right) x^{*} \\
& W 2_{j}=\max \left(p_{2}-c_{2 j}\right)\left(1-x^{*}\right) .
\end{aligned}
$$

We characterize the conversion period as a multistage game with observed actions. In this stage, each firm knows the actions of all other firms in the past stages, but they move simultaneously within each stage and will thus simultaneously reset their prices when any firm changes its technology applied to the product. As typical for such games, the solution is obtained by considering the best response functions of each firm when given the technology choice of the other firm.

For example, in Segment 1, the demand of Firm 1 is

$$
x=\frac{K_{e}-p_{1}+p_{2}}{2 K_{e}} .
$$

Thus, the profit function of the firms with established old technology is

$$
\begin{aligned}
& W 1_{e}=\left(p_{1}-c_{e}\right) x \\
& W 2_{e}=\left(p_{2}-c_{e}-y\right)(1-x) .
\end{aligned}
$$

Their price response function is

$$
\begin{aligned}
& \partial_{p 1} W 1_{e}=-\frac{-c_{e}+p_{1}}{2 K_{e}}+\frac{K_{e}-p_{1}+p_{2}}{2 K_{e}}=0 \\
& \partial_{p 2} W 2_{e}=1-\frac{K_{e}-p_{1}+p_{2}}{2 K_{e}}-\frac{-c_{e}+p_{2}-y}{2 K_{e}}=0 .
\end{aligned}
$$

Solving this equation, we can obtain the optimal price of the two firms as

$$
p_{1}=\frac{1}{3}\left(3 c_{e}+3 K_{e}+y\right)
$$




$$
p_{2}=\frac{1}{3}\left(3 c_{e}+3 K_{e}+2 y\right) .
$$

The demand of Firm 1 will be $x=\frac{3 K_{e}+y}{6 K_{e}}<1$, with the limit $3 K_{e}>y$.

Finally, we can obtain the profit of the two firms in the period of Segment 1:

$$
\begin{aligned}
W_{1}^{e e} & =\frac{\left(3 K_{e}+y\right)^{2}}{18 K_{e}} \\
W_{2}^{e e} & =\frac{\left(3 K_{e}-y\right)^{2}}{18 K_{e}} .
\end{aligned}
$$

Similarly, we can obtain the profit of the two firms in the period of Segment 2:

$$
\begin{aligned}
W_{1}^{n e} & =\frac{\left(c_{e}-c_{n}+2 K_{e}+K_{n}-b(t) K_{n}+y\right)^{2}}{9\left(K_{e}+K_{n}\right)} \\
W_{2}^{n e} & =\frac{\left(-c_{e}+c_{n}+K_{e}+2 K_{n}+b(t) K_{n}-y\right)^{2}}{9\left(K_{e}+K_{n}\right)} .
\end{aligned}
$$

Firm 1 will balance the profits in the two segments to select the optimal conversion time $T 1 f$, and the total profit for Firm 1 in the whole period $(0-T)$ is

$$
\mathrm{TW}_{1}=\max \left(\int_{0}^{T 1 f} W_{1}^{e e} \mathrm{~d} t+\int_{T 1 f}^{T} W_{1}^{n e} \mathrm{~d} t\right) .
$$

The optimal time is

$$
T 1 f=\frac{-2 c_{e}+2 c_{n}-4 K_{e}-2 K_{n}+2 b K_{n}-2 y+\sqrt{2}\left(3 K_{e}+y\right) \sqrt{\frac{K_{e}+K_{n}}{K_{e}}}}{2 k K_{n}} .
$$

\subsection{Firm 2 monopolizes the new technology}

When inferior enterprises (Firm 2) in the old market monopolize new technologies, they must also experience competition in the old market (Segment 1) and the process of new technology conversion (Segment 2). A new technology's comprehensive performance is relatively poor at the beginning, and it cannot directly replace the old technology. Using the steps similar to the above analysis, we can determine that in Segment 1, the profit of the firms is the same as the above:

$$
\begin{aligned}
W_{1}^{e e} & =\frac{\left(3 K_{e}+y\right)^{2}}{18 K_{e}} \\
W_{2}^{e e} & =\frac{\left(3 K_{e}-y\right)^{2}}{18 K_{e}} .
\end{aligned}
$$

We can regain the profits in Segment 2 when Firm 2 converts to the new technology:

$$
\begin{aligned}
W_{1}^{e n} & =\frac{\left(-c_{e}+c_{n}+K_{e}+2 K_{n}+b K_{n}-k K_{n} t\right)^{2}}{9\left(K_{e}+K_{n}\right)} \\
W_{2}^{e n} & =\frac{\left(c_{e}-c_{n}+2 K_{e}+K_{n}-b K_{n}+k K_{n} t\right)^{2}}{9\left(K_{e}+K_{n}\right)} .
\end{aligned}
$$

Firm 2 balances the profits in the two segments to select the optimal conversion time $T 2 f$, and the total profit for Firm 2 in the whole period $(0-T)$ is

$$
\mathrm{TW}_{2}=\max \left(\int_{0}^{T 2 f} W_{2}^{e e} \mathrm{~d} t+\int_{T 2 f}^{T} W_{2}^{e n} \mathrm{~d} t\right)
$$


The optimal time is

$$
T 2 f=\frac{-2 c_{e}+2 c_{n}-4 K_{e}-2 K_{n}+2 b K_{n}+\sqrt{2}\left(3 K_{e}-y\right) \sqrt{\frac{K_{e}+K_{n}}{K_{e}}}}{2 k K_{n}} .
$$

\subsection{Analysis}

As new technologies mature, companies can select between technology alternatives. Different from the those in the traditional monopoly model (only one enterprise in the market), the advantages or disadvantages in the old market in a competitive environment affect the timing of the adoption of new technologies via technology monopolies. For example, consider the condition of dominant Firm 1. In the first stage (Segment 1), the advantage in the old market will make Firm 1 obtain high profits. As the new technology matures, this advantage will require a high competitive advantage for the new technology to make the enterprise interested in its adoption. In the second stage (Segment 2), Firm 1's advantage of the old technology faces a relatively weak old technology by Firm 2 in the adoption choice of the new technology. In turn, this condition promotes the enterprise's advanced adoption of the new technology. By contrast, for inferior Firm 2 to monopolize the technology, its disadvantage in the first stage will reduce the requirements for the competitiveness of the new technology. However, this disadvantage will delay Firm 2's adoption of the new technology in the second stage because it is faced with an advanced old technology. For the effect of the advantages and disadvantages of the old market on the timing of adoption of new technologies, we make the following proposition:

Proposition 4.1. If the firm can monopolize the new disruptive technology, it will adopt the new technology early if the firm and the competitor's strength gap (the strength gap in our model is y) is large.

When the firm converts to the new technology, the value of the new technology must be higher than that of the old technology. Moreover, the whole value of the market with the competition between the old and new technologies will be higher than that with the competition between the old technologies. Thus, for the advantaged firm that monopolizes the new technology, if the strength gap is high, the profit increase in the new market would be higher than that lost in the old market. For the disadvantaged firm that monopolizes the new technology, it will be forced to narrow the large gap by converting to the new technology early.

Proposition 4.2. When the disadvantaged firm in the old market monopolizes new technologies, new technologies will enter the market early.

For the market, the entry of new technologies often leads to the satisfaction of new demands or the improvement of social values. Especially for new technologies in asymmetric competition, the newly introduced quality dimension can effectively serve consumer-related needs. Even if the new technology is immature, it will still generate high value and satisfaction for consumers. Thus, having inferior firms or entrants developing the new disruptive technology is preferred.

\section{Symmetric COMPetition Under EXternal AUthorization}

We consider the case in which the new technology is licensed by other third-party organizations (e.g., a college or research institute), and both firms in the market must pay royalties to adopt the new technology; we assume the fee as fixed $K$. The roles of market competition and technology decisions are captured using the following variation of Cournot competition model [10].

\subsection{Benchmark model}

The market structure in any period and the production decisions of these firms depend on the introduction decisions made by the firms and the outcome of new technology development. Thus, market competition is always coupled with the technology competition as shown in Figure 4. 


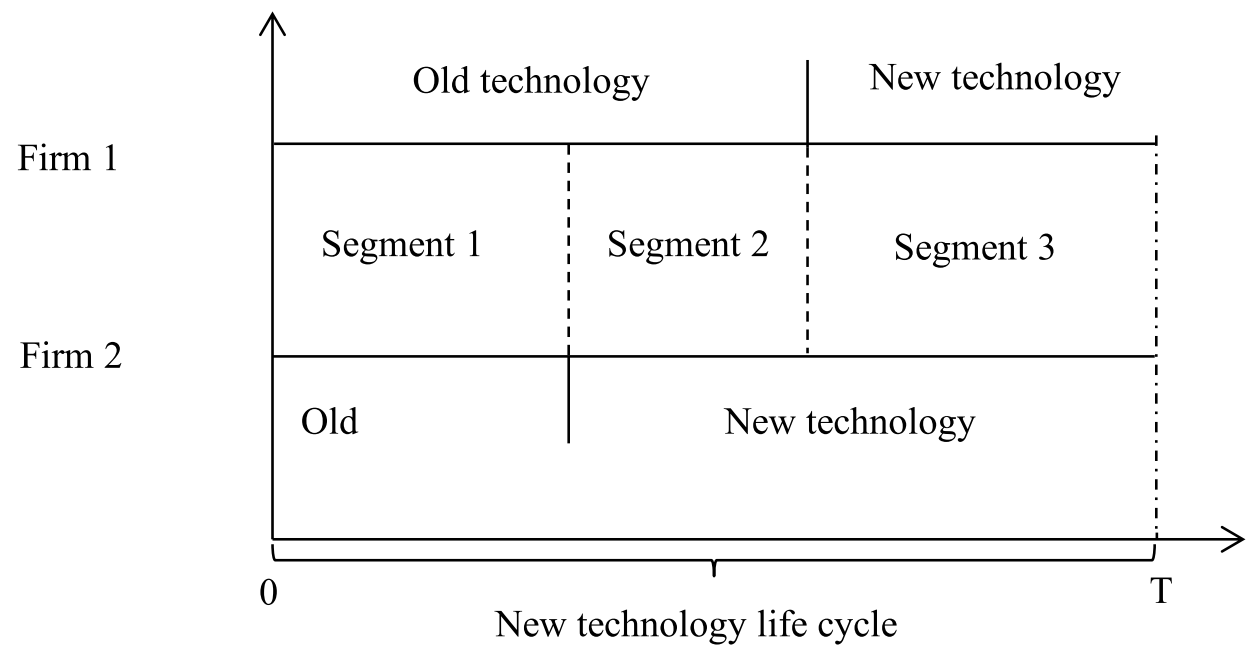

FIgURE 4. Firm competition and technology competition.

Similar to our approach in the monopoly model, we first define the demand function as follows:

Firms 1 and 2 compete on technology $e$ :

$$
p_{1}+k_{e} x=p_{2}+k_{e}(1-x) .
$$

Firm 1 first changes to technology $n$, whereas Firm 2 retains technology $e$ :

$$
p_{1}+k_{n}[x+b(t)]=p_{2}+k_{e}(1-x) .
$$

Firm 1 retains technology $e$, whereas Firm 2 first changes to technology $n$ :

$$
p_{1}+k_{e} x=p_{2}+k_{n}[1+b(t)-x] .
$$

Firms 1 and 2 simultaneously compete on technology $n$ :

$$
p_{1}+k_{n}[x+b(t)]=p_{2}+k_{n}[1+b(t)-x]
$$

Under each situation, the firm will have a Cournot duopoly game on the price to maximize their profit:

$$
\begin{aligned}
& W 1_{j}=\max \left(p_{1}-c_{1 j}\right) x^{*} \\
& W 2_{j}=\max \left(p_{2}-c_{2 j}\right)\left(1-x^{*}\right) .
\end{aligned}
$$

As typical for such games, the solution is obtained by considering the best response functions of each firm, given the technology choice of the other firms. Herein, we provide the equilibrium result of the technology competition above in Table 3 .

\subsection{Analysis}

For the adoption of a new technology under asymmetric competition, whether the new technology will substitute the old or not is unclear. In the transistor industry's early years, for example, it was unclear whether germanium or silicon transistors have prevailed. Similarly, in the electronic watch industry, models with lightemitting diodes (LED) and liquid crystal displays (LCDs) dueled for market acceptance. In several instances, the new technology may never gain widespread acceptance. Most of the examined firms made substantial 
TABLE 3. Equilibrium profits under different technology selections at time $t$.

\begin{tabular}{|c|c|c|c|}
\hline \multirow{2}{*}{\multicolumn{2}{|c|}{ Profit }} & \multicolumn{2}{|c|}{ Firm 2} \\
\hline & & Technology $e$ & Technology $n$ \\
\hline \multirow[t]{2}{*}{ Firm 1} & Technology $e$ & $W_{1}^{e e}, W_{2}^{e e}$ & $W_{1}^{e n}, W_{2}^{e n}$ \\
\hline & Technology $n$ & $W_{1}^{n e}, W_{2}^{n e}$ & $W_{1}^{n n}, W_{2}^{n n}$ \\
\hline \multicolumn{4}{|c|}{$W_{1}^{e e}=\frac{\left(3 K_{e}+y\right)^{2}}{18 K_{e}}$} \\
\hline \multicolumn{4}{|c|}{$W_{2}^{e e}=\frac{\left(3 K_{e}-y\right)^{2}}{18 K_{e}}$} \\
\hline \multicolumn{4}{|c|}{$W_{1}^{e n}=\frac{\left(-c_{e}+c_{n}+K_{e}+2 K_{n}+b K_{n}-k K_{n} t\right)^{2}}{9\left(K_{e}+K_{n}\right)}$} \\
\hline \multicolumn{4}{|c|}{$W_{2}^{e n}=\frac{\left(c_{e}-c_{n}+2 K_{e}+K_{n}-b K_{n}+k K_{n} t\right)^{2}}{9\left(K_{e}+K_{n}\right)}-K$} \\
\hline \multicolumn{4}{|c|}{$W_{1}^{n e}=\frac{\left(c_{e}-c_{n}+2 K_{e}+K_{n}-b K_{n}+k K_{n} t+y\right)^{2}}{9\left(K_{e}+K_{n}\right)}-K$} \\
\hline \multicolumn{4}{|c|}{$W_{2}^{n e}=\frac{\left(-c_{e}+c_{n}+K_{e}+2 K_{n}+b K_{n}-k K_{n} t-y\right)^{2}}{9\left(K_{e}+K_{n}\right)}$} \\
\hline \multicolumn{4}{|c|}{$W_{1}^{n n}=-K+\frac{K_{n}}{2}$} \\
\hline \multicolumn{4}{|c|}{$W_{2}^{n n}=-K+\frac{K_{n}}{2}$} \\
\hline
\end{tabular}

commitments over time, but these investments were made only after the potential of the new product became apparent. Such firms seemed to harbor the expectation (initially) that the new product would not penetrate the core markets of the traditional business. In several cases, concerns were also raised that the new product's early imperfections could tarnish the firm's reputation; as such, reluctance to make a full commitment existed until the product was "proven". Since firms only passively accept new technologies and cannot predict the future development limits of new technologies, they can only make decisions on the basis of the current profitability of the technology. We assume that at any time $t$, the two firms are under a Cournot game in the adoption problem of the new technology.

At $t=0$, the new technology is a "worse" technology, and the equilibrium of the Cournot game is that both firms will keep the old technology. However, with the development of the new technology, the gap with the old technology in the inferior performance dimension will shrink, and the original equilibrium will break. Table 3 summarizes each firm's payoffs for the four possible technology adoption strategy pairs, where at any time $t$, each firm selects between a strategy of adopting the new technology or not, given the other firms' choices.

Proposition 5.1. If the licensing fees are not high and the gap between firms (y in our model) in the old market is not large, the inferior firm in the old market will adopt the new technology earlier than the market leader. Otherwise, the market leader will be the first mover, and the other firm will not adopt the new technology.

When new technologies are developed and authorized by third-party organizations and a competitive relationship exists between technologies, the firms will face high uncertainty, and they can only make decisions with current profits. This instance is highly affected by the authorization fee and market competition. Proposition 5.1 states that when the licensing fees are not considerably high and the strengths and weaknesses in the old market are not evident, the original disadvantaged firm will prioritize the adoption of the new technology. However, if the licensing fee is high and the advantages of large firms in the old market are evident, small firms will not participate in the competition for such new technology.

Proposition 5.2. When the inferior firm adopts the new technology, the market condition will be as follows:

(1) If the strength gap between firms (y in our model) is low, then, the market leader will quickly lose its advantageous position.

(2) If the strength gap is at a medium level and the licensing fee is low, then, the market leader will keep its profit higher than the competitor but lose some market share. 
(3) If the licensing fee is at a medium level and the strength gap between firms is high, then, the market leader will retain its market position with a higher market share and higher profit than its competitor.

A dangerous area is observed for the market leader in the old market. During the period of competition between technologies, if small firms adopt the new technology and the market share and profits of the market leader are surpassed, then, the market leader will be alerted. The market leader can promptly take relevant measures to avoid the change in market leadership. However, in the dangerous areas described above, especially when the market leader's market share and profit are maintained higher than those of their competitors, the market leader faces difficulty in detecting new technologies or new companies' threats to themselves. Moreover, if the new technologies can still be improved, the market leader in the old market tends to face the risk of losing its leadership position. More importantly, for the asymmetric competition between technologies, inferior firms are likely to disrupt the market leader with market control.

Proposition 5.3. If the firm is late in the timing of updating the new disruptive technology, then, it will be delayed again $\left(T_{i}^{l}\right)$ relative to its previous optimal time $\left(T_{i}^{f}\right)$ because of the market competition effect.

Proposition 5.1 shows that the competition of technology can cause the superior firms to delay their updates on the new technology. Meanwhile, firm competition can also cause a delay in timing the new technology as described in Proposition 5.3. The internal principle is easy: if more firms have taken the new technology, then, the competition intensity will be high, and the profit will be low. Consequently, the firm is delayed in taking the new technology.

\subsection{Discussion and managerial implication}

In the previous section, we introduced the adoption of disruptive technologies by enterprises in symmetric competition under the influence of technology competition. Previous research about new product introduction time never considered the boundary in which a new technology will disrupt the old one because newer advanced technology may offer improved performance. Thus, considering the competition from rivals and maximizing the profit from the new technology allows the company to strategize the technology adoption choice. In contrast, our results show the lag in the adoption of disruptive technologies by leading companies in competition. As shown in Figure 5 , when $y=0$, which means that the two competitors have the same competitive advantage, the boundary of technological substitution should be $T^{f}$. This is the time that profit growth from disruptive technologies $W_{i}^{n}$ outstripped that $W_{i}^{e}$ of old ones. However, when $y>0$, firms will face different effects of competition. The superior firm (Firm 1) will get the new profits $W_{1}^{e e}$ and $W_{1}^{n e}$, and they are all higher than previous profits $W_{i}^{n}$ and $W_{i}^{e}$. The inferior firm (Firm 2) will get a lower profit $W_{2}^{e e}$ because of its disadvantage, and the expect profit of from the disruptive technologies is not change. As a result, we will encounter the situation described in Proposition 5.1, that is, under certain conditions, the investment time of inferior enterprises is earlier.

The reason is that the technology boundaries of the two kinds of technology are blurred by the competition, and the net effect of technology competition shows a complex interplay. Proposition 5.2 clarifies the profit and market share of the superior firm after the inferior firm adopts new disruptive technologies, as shown in Figure 6. In the case of Segment 1, the severe loss in profit and market share will cause the superior firm to respond positively to the adoption of new disruptive technologies. In Segment 2, the superior firm can also discover the disruptive effects of new technologies in time through the loss of market share. The dangerous condition is the Segment 3, the adoption of disruptive technologies that were at a disadvantage in the early stage does not arouse warnings from the superior firm.

In the process of adopting disruptive technologies, the superior firms at Segment 3 need to pay more attention to corresponding market erosion risks. Competition will further exacerbate the delayed response of them to the timing of adopting new technologies. As illustrated in Proposition 5.3, it will be delayed again as the profit increases from new technology will typically be eliminated by the increased competition facilitated by the new technology. 


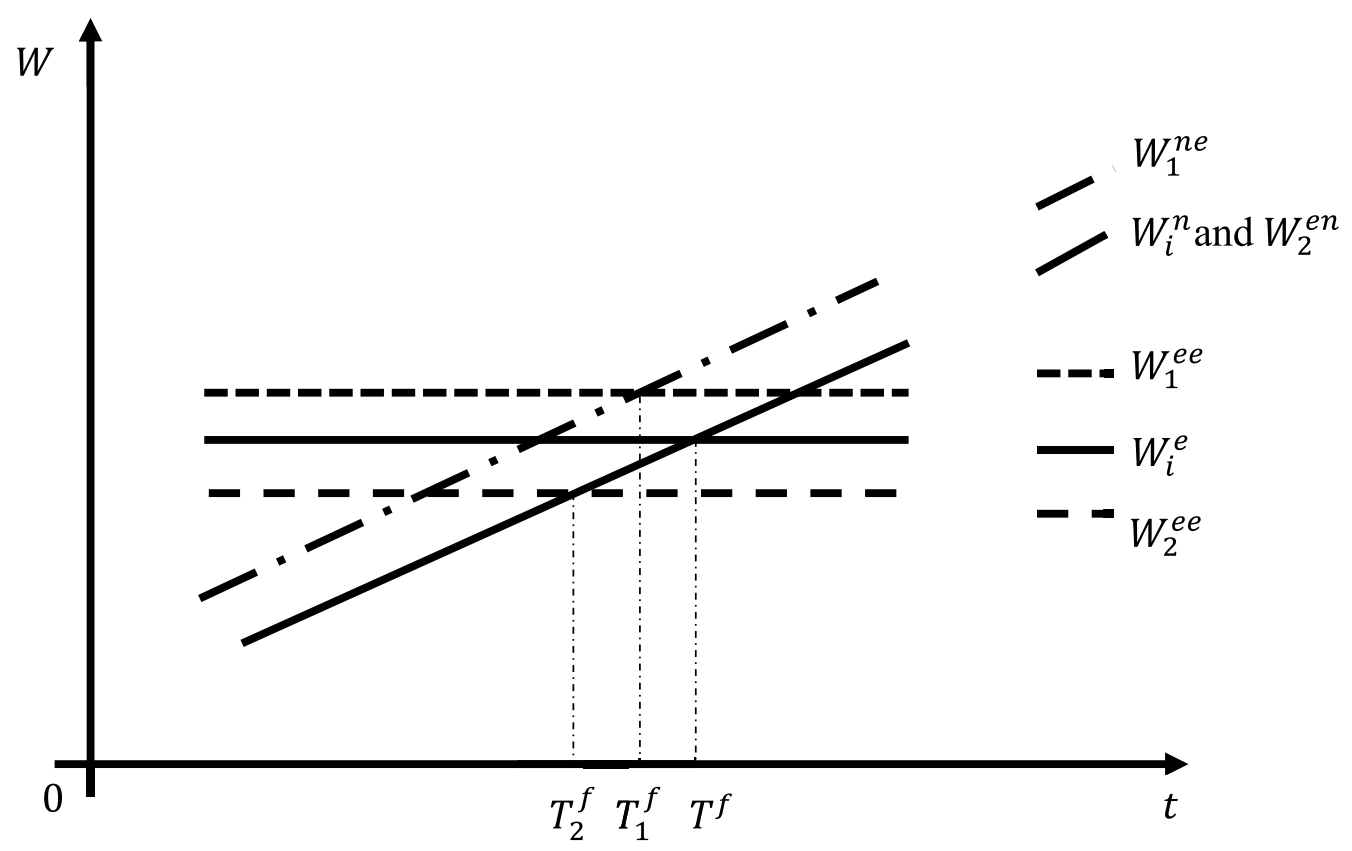

Figure 5. The adoption time under symmetric competition.

\section{Asymmetric COMPetition And PREemption STRATEgy}

In making decisions concerning competitive strategy, firms from an established, threatened industry have a substantial base of experience to draw upon. However, our analysis shows that if the new technology requires or enables different product concepts or ways of competing, strategic approaches based on conventional wisdom to behave as a "profit center" may be less likely to succeed. In order to reduce the impact of related competition, based on the "Red Queen" hypothesis in the empirical research on dynamic competition, we introduce a new competitive strategy that is different from traditional "profit centers" - the preemption strategy. That is, improving as quickly as possible to maintain a static advantage over the competitors in a complex competition.

To make our study comprehensive, we compare the different responses of asymmetric competitors-the incumbent competitors and the entrants-to the preemption strategy adopted by market leaders and analyze the related competitive results. We address the question of whether or not the market leader can preempt the next-generation advantage when facing different competitive pressures. In reality, the only competition happens between the market leader and the incumbent at the beginning. The threat of the entrant is a potential competition consideration of the market leader (Fig. 7).

\subsection{The established competition}

The market leader and the other incumbents in the market will balance the profits of leading the next generation or following it.

For the market leader (Firm 1), the leading profits of the next generation could be

$$
W_{1}^{n e}=\frac{\left(c_{e}-c_{n}+2 K_{e}+K_{n}-b K_{n}+k K_{n} t+y\right)^{2}}{9\left(K e+K_{n}\right)}-K .
$$




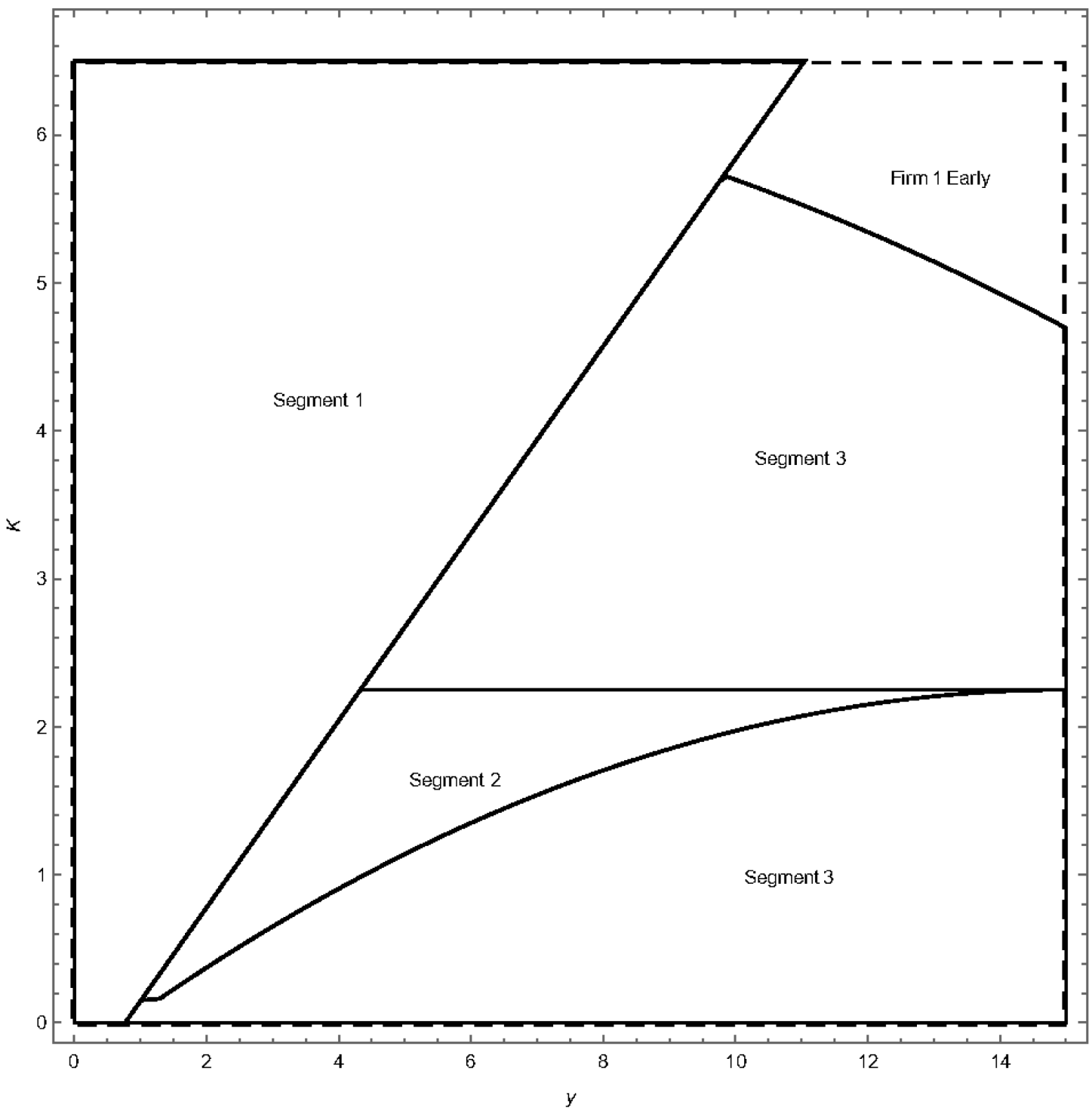

Figure 6. Schematic diagram of Proposition 5.2.

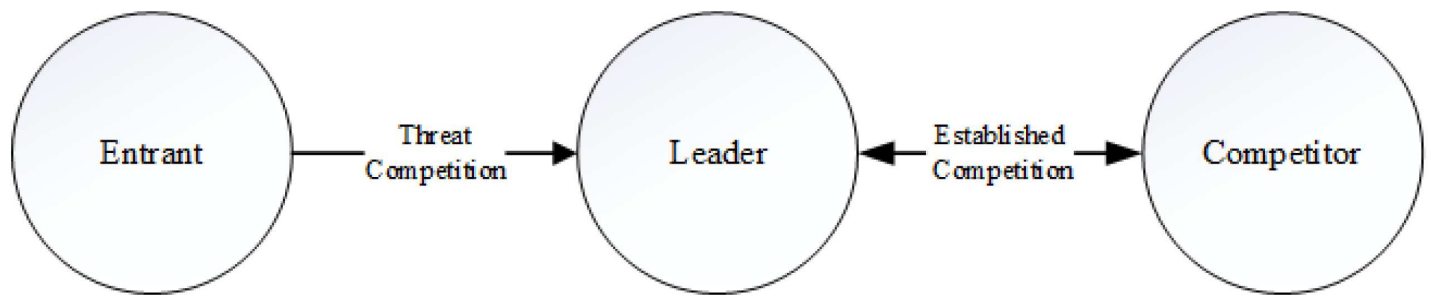

FIgURE 7 . The extended market competition. 
The following profits could be

$$
W_{1}^{e n}=\frac{\left(-c_{e}+c_{n}+K_{e}+2 K_{n}+b K_{n}-k K_{n} t\right)^{2}}{9\left(K_{e}+K_{n}\right)} .
$$

Let $W_{1}^{n e}=W_{1}^{e n}$, the adoption time could be

$$
T 1=\frac{-3 K_{e}^{2}+9 K_{e} K+6 b K_{e} K_{n}+9 K K_{n}+3 K_{n}^{2}+6 b K_{n}^{2}-4 K_{e} y-2 K_{n} y+2 b K_{n} y-y^{2}-2\left(c_{e}-c_{n}\right)\left(3 K_{e}+3 K_{n}+y\right)}{2 k K_{n}\left(3 K_{e}+3 K_{n}+y\right)} .
$$

For the incumbent competitor, the leading profits of the next generation could be

$$
W_{2}^{e n}=\frac{\left(c_{e}-c_{n}+2 K_{e}+K_{n}-b K_{n}+k K_{n} t\right)^{2}}{9\left(K_{e}+K_{n}\right)}-K
$$

The following profits could be

$$
W_{2}^{n e}=\frac{\left(-c_{e}+c_{n}+K_{e}+2 K_{n}+b K_{n}-k K_{n} t-y\right)^{2}}{9\left(K_{e}+K_{n}\right)} .
$$

The optimal time will be

$$
T 2=\frac{-3 K_{e}^{2}+9 K_{e} K+6 b K_{e} K_{n}+9 K K_{n}+3 K_{n}^{2}+6 b K_{n}^{2}+\left(c_{n}-c_{e}\right)\left(6 K_{e}+6 K_{n}-2 y\right)-2 K_{e} y-4 K_{n} y-2 b K_{n} y+y^{2}}{2 k K_{n}\left(3 K_{e}+3 K_{n}-y\right)} .
$$

Proposition 6.1. In order to maintain long-term competitive advantage in the market, the market leader can preempt the adoption of the disruptive technology, which earlier than the incumbent competitor.

To behave as a "profit center", the market leader will fall into the trap of short-term profit maximization, thereby losing the competitive advantage of the next-generation technology. Proposition 6.1 shows that the market leader can use the preemption strategy to avoid the relevant situation. This strategy suggests that in intensely competitive or hypercompetitive markets, firms with leading or dominant market positions should cannibalize their own current advantages in product, process, and knowledge with next-generation advantages before the competitors stepping in to steal the market.

\subsection{The threat of the entrant}

The entrant will enter the market when the new technology could be profitable. If it does enter the market, then, it will face competition from the market leader. For the entrant, the acceptable condition to enter the market could be

$$
W_{2}^{e n}=\frac{\left(c_{e}-c_{n}+2 K_{e}+K_{n}-b K_{n}+k K_{n} t\right)^{2}}{9\left(K_{e}+K_{n}\right)}-K>0 .
$$

The time is

$$
T 3=\frac{\left(c_{n}-c_{e}\right) k K_{n}-2 k K_{e} K_{n}-k K_{n}^{2}+b k K_{n}^{2}+3\left(K_{e}+K_{n}\right) \sqrt{\frac{k^{2} K K_{n}^{2}}{K_{e}+K_{n}}}}{k^{2} K_{n}^{2}} .
$$

Proposition 6.2. The entrant without the care of the previous market will adopt the new technology earlier than the ideal preemption time of the market leader. 


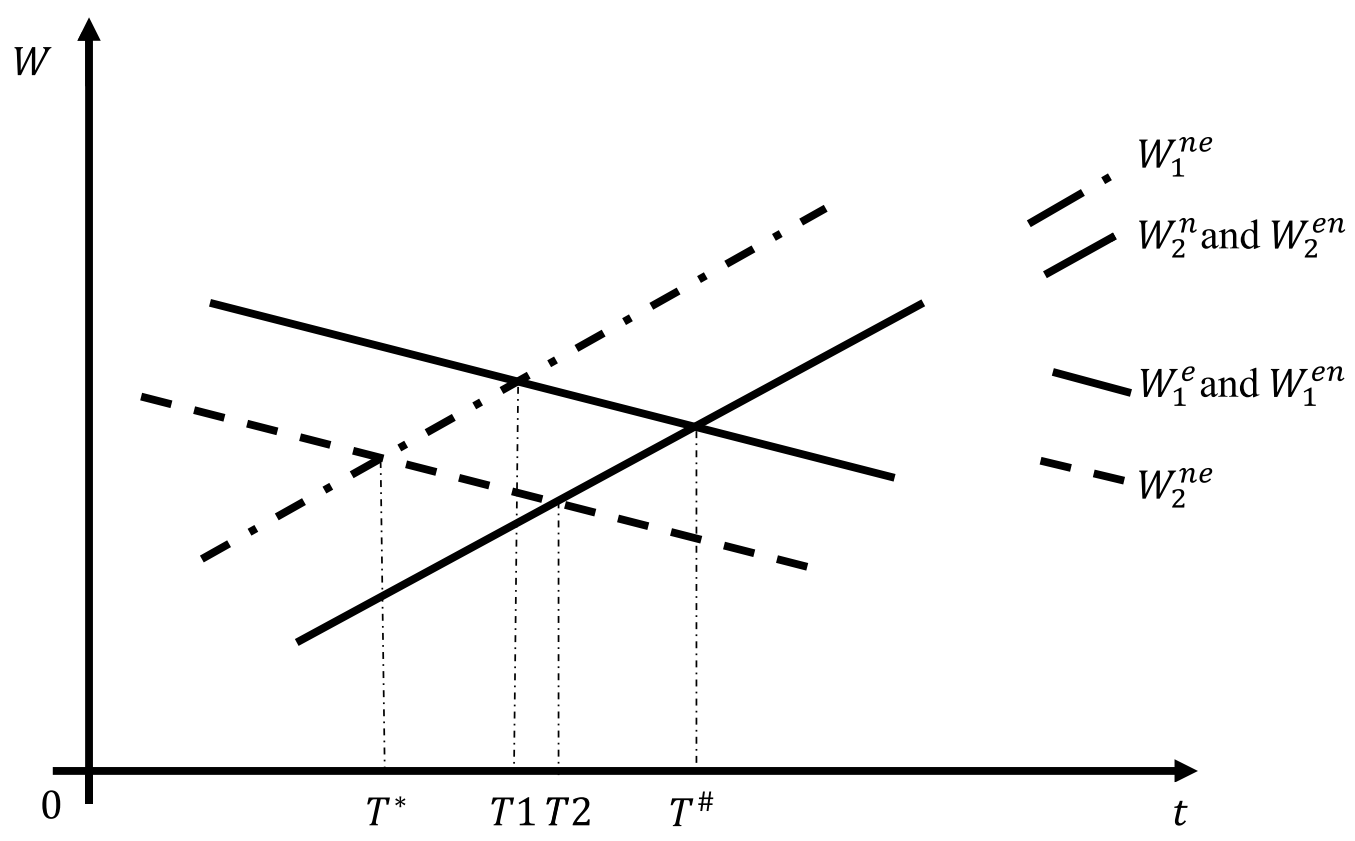

FiguRE 8 . The adoption time of preemption strategy.

Different from the symmetric competition, entrants have different competitive motivations in adopting disruptive technologies compared to existing firms in the market. Research observations on disruptive innovation show that new entrants are pioneering in adopting new technologies. Relevant explanations are mainly focused on the decision-making errors and the bloated structure of the market leaders, Proposition 6.2 showed that the market leader's acceptable time for adoption is still later than the time for the entrants to enter the market, even if the market leader preempts the adoption of the disruptive technology.

\subsection{Comparisons and managerial implications}

In today's market, even if companies have a more comprehensive understanding of the risks of disruptive technologies, they still lack effective solutions for adopting disruptive new technologies. By comparing the competitive reactions of different competitors, we can find that the market leader still faces a dilemma in the process of actively adopting disruptive technologies.

Proposition 6.3. The market leader will lose the current leader position to the incumbent competitor if it preempts to deter the entrant.

As shown by Proposition 6.3, for the reaction of the market leader, a dilemma position will exist: defending the entrant threat before the new technology proves valuable will cause the market leader to lose its position relative to the incumbent competitor. In other words, in the face of asymmetric competition between technologies and between firms, the complex coupling reaction prevents us from getting a convincing optimal solution for the adoption of disruptive technologies. Fear of stepping into the wrong technological path, the market leader cannot adopt disruptive technologies prematurely. However, we can introduce a solution that allows leaders to maintain their competitive position while minimizing losses.

We first ignore the threat of competition from new entrants and analyze the established competition under the preemption strategy. As shown in Figure 8, when $y=0$, the optimal time to adopt a new technology for society is $T^{\#}$, as the profit from the new disruptive technology $W_{2}^{n}$ is higher than that $W_{1}^{e}$ from the old 
TABLE 4. The sale data of camera.

\begin{tabular}{lllll}
\hline \hline Year & $\begin{array}{l}\text { Quantity of FC } \\
\text { Unit:1000 pcs }\end{array}$ & $\begin{array}{l}\text { Quantity of DC } \\
\text { Unit:1000 pcs }\end{array}$ & $\begin{array}{l}\text { Value of FC } \\
\text { Unit: Million Yen }\end{array}$ & $\begin{array}{l}\text { Value of DC } \\
\text { Unit: Million Yen }\end{array}$ \\
\hline 1997 & 36671 & 606 & 375017 & 57463 \\
1998 & 36000 & 1030 & 384223 & 116852 \\
1999 & 33879 & 5088 & 358842 & 227903 \\
2000 & 31719 & 10342 & 302008 & 437979 \\
2001 & 27599 & 14753 & 239884 & 545434 \\
2002 & 23660 & 24551 & 200013 & 797671 \\
2003 & 16296 & 43408 & 118149 & 1225043 \\
2004 & 10056 & 59766 & 53980 & 1546010 \\
2005 & 5380 & 64766 & 24702 & 1558626 \\
\hline
\end{tabular}

Notes. Source: Adapted from CIPA, and FC = Film Camera, DC = Digital Camera.

technology. However, when $y>0$, we can get that the profit $W_{1}^{n e}$ from the new disruptive technology by Firm 1 will be higher and the profit $W_{2}^{\text {ne }}$ from the old technology by Firm 2 will be lower. Thus, they will have different preemption time as we have provided in Proposition 6.1. The market leader's preemption time is early, because the loss of profits in the late adoption of new technologies is higher than that of competitors, and the preemption of competitors is mainly due to their disadvantages in the old technologies.

Proposition 6.4. The most acceptable time of the market leader for new technology adoption would be between the interval $\left[T^{*}, T^{\#}\right]$. Considering a strategic preemption competitor, the time should be early than T2, while considering the threat of entrant, the earliest time could be $T^{*}$.

The core of our preemption strategy is trying to adopt disruptive technologies earlier and reduce related profit losses while maintaining the leader position. In reality, any time earlier than the socially optimal time $T^{\#}$ has the possibility to avoid the loss of the leader position. According to the competitive tendency of different firms, they can choose different timing strategies. When there are aggressive competitors, the market leader can reduce the loss of profits gained from new technologies by investing in advance. On the premise of avoiding falling into the wrong technological path, the earliest investment time could be the time $T^{*}$ that maintain current leader position while pursuing future competitive position.

\section{Practical application: the example of KodaK}

In this section we examine how the digital photography diffusion/substitution process might reflected in our framework-a typical case often used as a disruptive technology. Our analysis progresses analogously to the way one would fit empirical data to the Bass [9] model. In fitting empirical digital photography data to our model, our goal is not to prove that the digital cameras are going through a disruptive substitution process of the type we describe. Rather, we simply seek to offer a plausible illustration of how such a "timing" decision might be made by the market leader-Kodak at that time. Our model is time decision-making, which is to discuss the entry time of the market leader, the competitors and even new entrants. The decision factor is to weigh the profit before and after investment.

\subsection{The relevant data and the firms' action strategy}

We obtained the sales of cameras in the world from CIPA, as shown in Table 4 and Figure 9.

We obtained annual reports from Kodak and Fuji, and searched the literatures to build an historical time line of the key events in digital photography and Kodak's and Fuji's response to this new technology. We looked at past Kodak and Fuji web sites on www.archive.org to get a sense of changes in marketing and strategy. The data is shown in Table 5 and Figure 10 as below. 


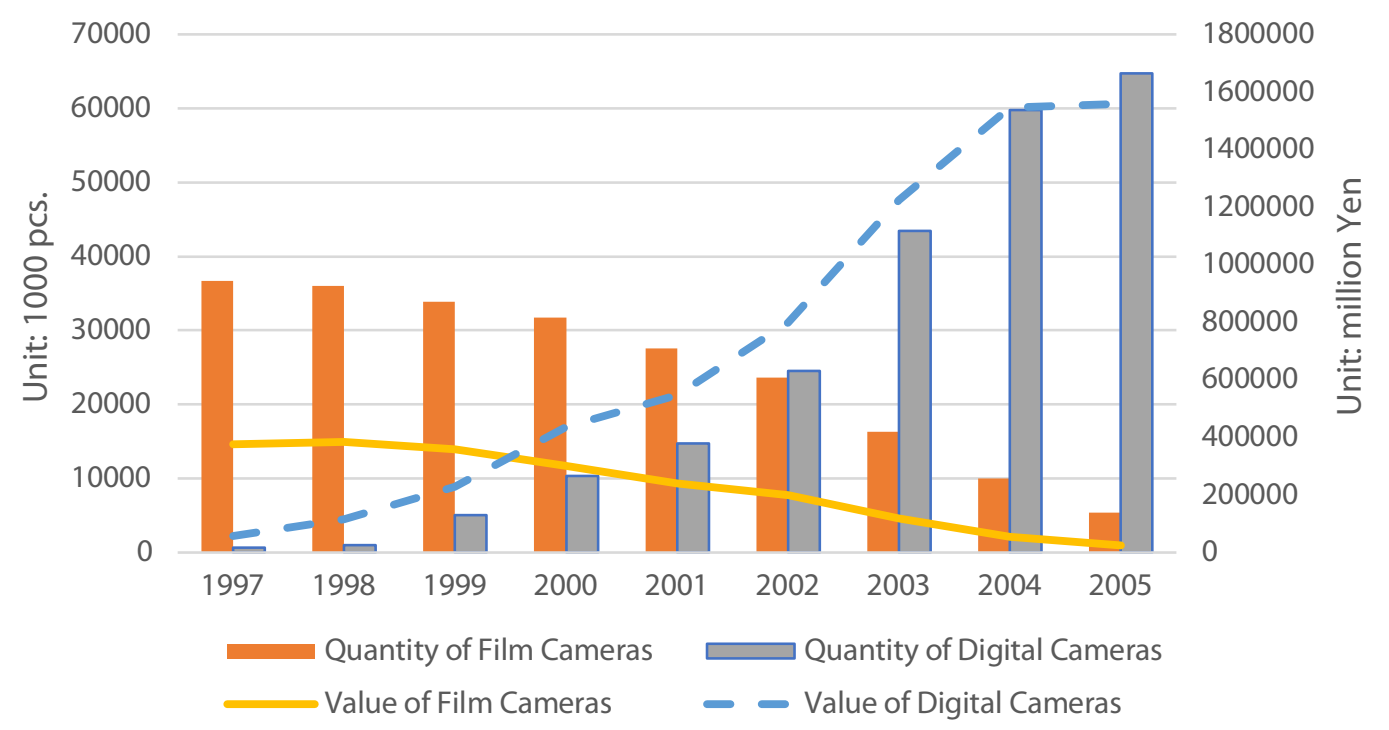

FIGURE 9. Sales of cameras.

TABle 5. The revenue comparation of Kodak and Fuji.

\begin{tabular}{lllll}
\hline \hline \multirow{2}{*}{ Year } & $\begin{array}{l}\text { Kodak NS } \\
\text { Unit: Million USD }\end{array}$ & $\begin{array}{l}\text { Fuji NS } \\
\text { Unit: Million USD }\end{array}$ & $\begin{array}{l}\text { Kodak MS } \\
\text { Unit Share }\end{array}$ & $\begin{array}{l}\text { Fuji MS } \\
\text { Unit Share }\end{array}$ \\
\hline \multirow{2}{*}{1996} & 15968 & 6226 & $48 \%$ & $27 \%$ \\
1997 & 14538 & 7185 & $46 \%$ & $29 \%$ \\
1998 & 13406 & 10892 & $42 \%$ & $31 \%$ \\
1999 & 14089 & 10620 & $40 \%$ & $33 \%$ \\
2000 & 13994 & 10912 & $38 \%$ & $35 \%$ \\
2001 & 13229 & 18190 & $36 \%$ & $37 \%$ \\
2002 & 12835 & 18982 & $34 \%$ & $39 \%$ \\
2003 & 12909 & 19397 & $32 \%$ & $41 \%$ \\
\hline
\end{tabular}

Notes. Source: Adapted from Merrill Lynch and Photo Market, NS = Net Sales, MS $=$ Market Shares.

The transformation from conventional photography to digital photography took about two decades. However, the origin of the great change for the firms needs to start in 1997. By 1997, digital camera sales were increasing by $75 \%$ a year while film camera sales increased by only $3 \%$. When photography moves from film to digital in 1998, it invited a whole new group of competitors into the marketplace such as Sony, Olympics. Between 1999 and 2000, the value of digital cameras sold passed the value of film cameras. By 2000, Fuji was one of the two leading digital camera manufacturers. In 2003, Kodak's annual report's chairman's letter stated that Kodak "implemented a digitally oriented strategy to support revenue and sustainable earnings". In the same year, Kodak closed its film camera factory in the US. We summary the key strategy transfer time in the Figure 11 below. 
Shares.

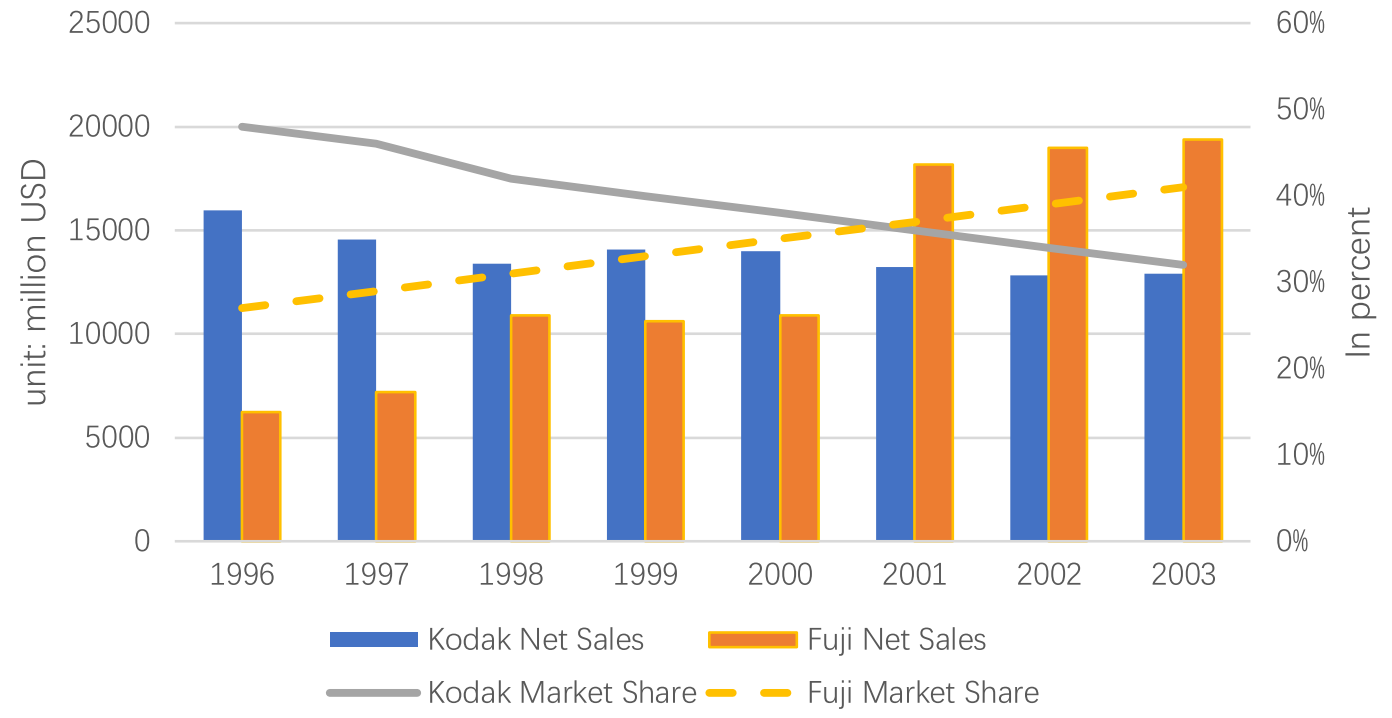

Figure 10. The sales and market share.

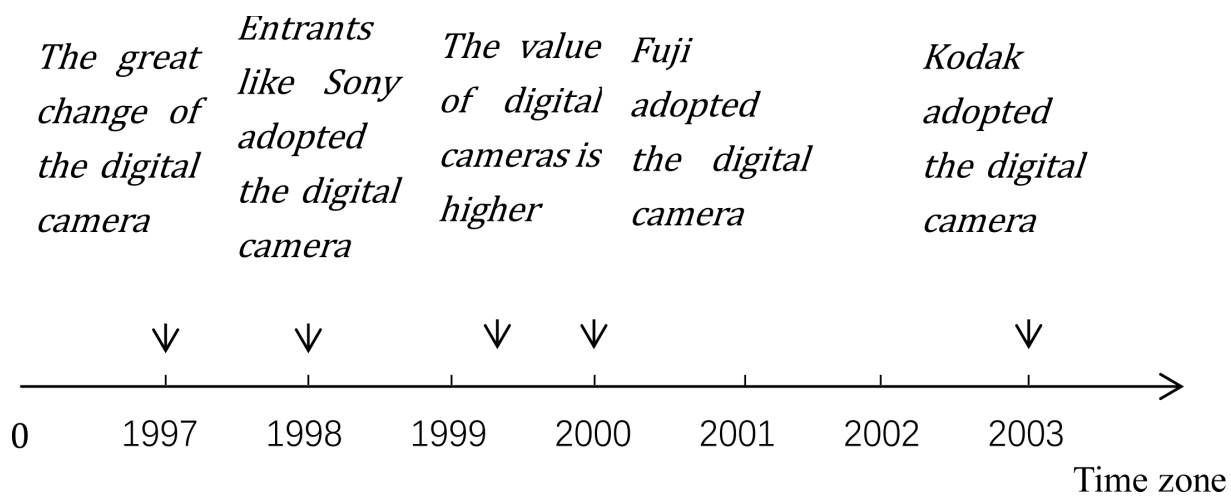

Figure 11. The time line.

\subsection{The application of our model}

A caveat in the analysis we perform here is that our model involves only a single old product sold by a single firm and a single new product sold by a single firm, whereas the actual camera industry is comprised of multiple products and firms. We proceed under the simplistic assumptions of our model, we only consider about the firms' main products which accounts for the largest share of the firm's sales, assuming that there is only one kind of new and old product, each sold by one competitor, and myopic decision-making on the timing of the adoption of the new product. Our intent is not to predict or duplicate specific numbers such as firm profits, but rather simply to depict the timing decision in terms of the competition effect from the incumbent competitors and threat from the entrants, and the technology competition changed over time. If one is instead trying to predict future sales quantities, then for that purpose the Bass model is a better modeling choice. We then use our model to simulate the process of timing decisions that Kodak had faced. This will help us have a clearer 


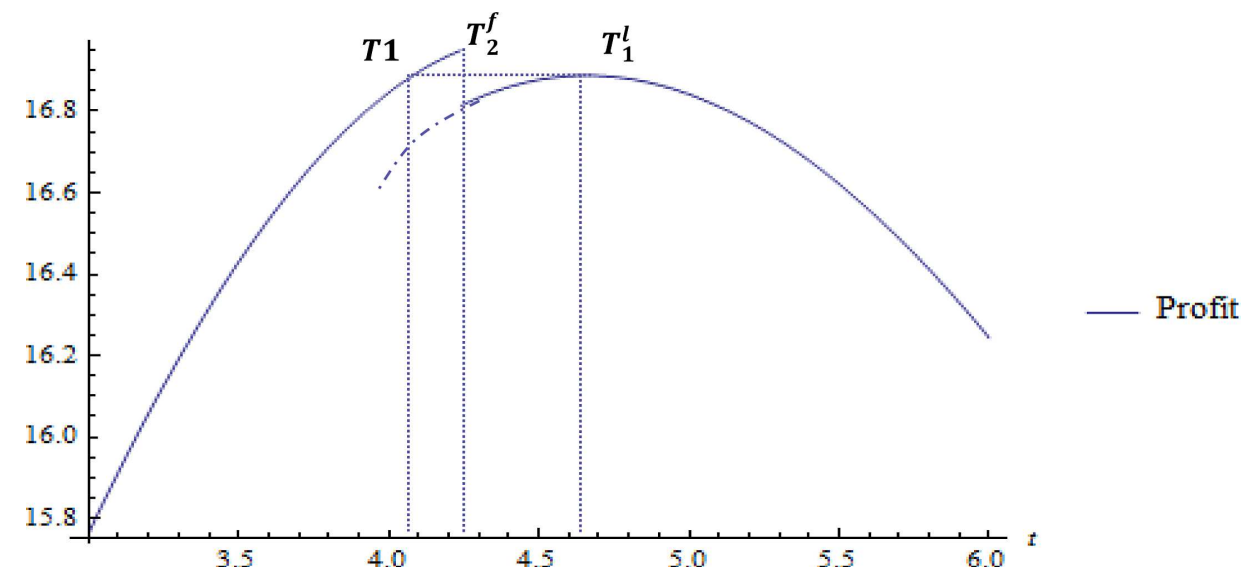

Figure 12. The whole profit of Firm 1 that updates to the new technology at time $t$.

understanding of Kodak's dilemma in the decision-making process and check whether Kodak as a well-managed firm had made a sub-optimal choice.

To simulate the situation that Kodak have faced, considering the time for Firm 1(Kodak) to adopt the new technology, it can be early than its incumbent competitor $T_{2}^{f}$, the same with $T_{2}^{f}$, or late than $T_{2}^{f}$. Let $t$ denote the time that the Firm 1(Kodak) may substitute the old product, we can get the profit function for Firm 1 affected by the incumbent competitor is as below, the result is shown in Figure 12.

$$
F(t)= \begin{cases}\int_{0}^{t} W_{1}^{e e} \mathrm{~d} t+\int_{t}^{T_{2}^{l}} W_{1}^{n e} \mathrm{~d} t+\int_{T_{2}^{l}}^{T} W_{1}^{n n} \mathrm{~d} t, & t<T_{2}^{f} \\ \int_{0}^{T_{2}^{f}} W_{1}^{e e} \mathrm{~d} t+\int_{T_{2}^{f}}^{T} W_{1}^{n n} \mathrm{~d} t, & t=T_{2}^{f} \\ \int_{0}^{T_{2}^{f}} W_{1}^{e e} \mathrm{~d} t+\int_{T_{2}^{f}}^{t} W_{1}^{e n} \mathrm{~d} t+\int_{t}^{T} W_{1}^{n n} \mathrm{~d} t, & t>T_{2}^{f} .\end{cases}
$$

Compare our time results (Fig. 12) with Kodak's choices in reality (Fig. 11), we can find that our model can perfectly explain this process. We have known that, the inferior firm in the old market will adopt the new technology earlier (at $T_{2}^{f}$ ) than the market leader as proved in Proposition 5.1. Kodak has fallen into the danger zone we have described in Proposition 5.2, that is when Fuji adopt the new disruptive technology in 2000, its profit and market share is still lower than Kodak as shown in Figure 10. Kodak is delayed again as the fierce competition in the digital market, which is the idea of Proposition 5.3. Then Kodak chose a time that is apparently much too late. Seen from Figure 12, it's clearly that Kodak has made a sup optimal choice. Kodak had tried to deter the entrants. In early 1998, Kodak outsourced most digital photographic equipment with Intel. However, Kodak encountered the dilemma position we have described in Proposition 6.3. The time is too early (early than $T 1$ ) that Kodak was losing $\$ 60$ on every digital camera it sold, and Kodak controlled the digital business lower than $25 \%$ in case of being caught off guard by Fuji. This equilibrium precisely describes the situation that in 1990s investing aggressively in the digital camera technology is not a rational financial decision, possibly at first this reason could have kept Kodak from investing. But Kodak began to develop a digital strategy long after it was obvious to everyone else that it needed one.

\subsection{The managerial suggestions of our model}

To behave as a "profit center", Kodak's failure was not a misjudgment in the traditional technological transformation, but the inability to do it. It was a contradiction. First of all, the film market had a higher barrier to entry, and there are relatively few firms that can compete with Kodak, such as Fuji Film. However, 
in the digital market, the threshold is relatively flat, and everyone has the opportunity to enter. As the market leader, Kodak is the first to be affected and Kodak is able to adopt radical investment methods compared to Fuji. The dilemma is that, Kodak's original size limits its more aggressive investment because it needs to maintain the current company size, what was worse, Fuji's impact on its traditional market is also considered. Contrast this with Sony Corp - the new entrant, as an electronics company, its organizational capabilities were far more aligned with what was needed to succeed. What's more, it jumped in early.

In this way, our preemption strategy might be a better choice. In this kind of complex inter-technologies and inter-firms' competition, maintaining one's own technological advantage by losing a certain amount of profit can help firms avoid being disrupted. More importantly, we have analyzed in detail the specific situation of the firm's implementation of preemption strategies. For example, our Proposition 6.4 have proved that the preemption strategy should not be later than the social time $T^{\#}$. As shown in Figure 9, that is early than the year 2000. More than that, compare the profit of Fuji and the value of the digital camera, the time $T^{*}$ that the Kodak can preempt might be earlier. Our suggestions can be effective as IBM Corp. did. From the early 1990s through the 2000s, IBM managed to do this very efficiently, exiting markets that included printer manufacturing, flat panel displays, personal computers, and disk drives. However, the solution in this case is cruel, the real challenge is keeping an innovation pipeline full of new products and services that can replace the old ones. As Kodak has shown, that can be a formidable challenge.

\section{Conclusion}

This study aims to help firms analyze the way in which the boundaries of the asymmetric competition between technologies change over time. This study also aims to determine the role played by the introduction timing and advantage in the old market in relieving or exacerbating the pressures of threat from competitors. Inspired by recent empirical observations of disruptive technologies and related research, we use a model of horizontal and vertical differentiation to explore how the technology boundary is shaped and changed over time. Using a contingency framework, we find a dangerous area for the market leader in the old market, that is, during the period of competition between technologies. If small firms adopt the new technology and the market leader's market share and profits are maintained higher than those of their competitors, then, the market leader faces difficulty in detecting new technologies or new companies' threats to themselves. Moreover, if the new technologies can still undergo improvement, then, the market leader in the old market is likely to face the risk of losing the leadership position.

As a "profit center", market leaders will inevitably lag behind in adopting disruptive technologies. To solve the problem of decision-making lag, inspired by the "Red Queen" hypothesis in the empirical research on dynamic competition, we introduce the preemption strategy for the market leaders in adopting the disruptive technologies. The result shows that the market leaders can avoid the short-run profit maximization trap by sacrificing some profits to preempt the adoption of disruptive technologies. More than that, we compared the influence of preemption strategy on the actions of market leaders in the symmetric competition and the asymmetric competition. We find a dilemma position that the market leader might encounter, that is, whether or not to preempt the new technology by losing its current leader position to the incumbent competitor. At last, on the premise of minimizing profit loss and ensuring market leadership, we provide a feasible decision-making area for the market leaders.

Our research expands the traditional single-dimensional technology adoption problem, taking the adoption of new disruptive technologies into account when there is asymmetric competition among technologies. We analyzed the coupling effect between technology competition and firm competition, and compared the influence of symmetric and asymmetric competition among firms on their decision-making. Under this circumstance, we have filled the gaps in relevant competitive research. In the end, compared with traditional research, we explain the dilemma of firms in the process of adopting disruptive technologies from a more rational perspective. More importantly, we provide certain theoretical suggestions for the actual operation of the market leaders. 
Our study is limited in that we assume that firms can only pursue one kind of technology as discussed in existing research $[4,20]$. Considering the tradeoff between the cost of diversification and the advantage of concentrated management, this assumption can also be reasonable and represent one direction of extension or future research for our study. We didn't consider other firm characteristics in terms of strength and weaknesses. We consider that when companies accept new technologies, their level is relatively balanced in our assumption. The assumption of relative balance can better show off the game dilemma behind it. Or else, if a new company has advantages over new technologies, then the original advantages of large companies will not have much meaning. And if large companies have advantages in new technologies, then this period will be a period of continuation of the advantages without producing relatively destructive results. Risks are also not all considered in the entire model, this is something that our model cannot cover. In terms of risk, researches have shown that large companies are conservative in risk, while small companies are risk-radical. As the disruptive technologies we studied, their own risks will be much higher than other types of new technologies. If you consider risks, the result will also make small companies more desire to enter early, which is not conducive to our description of the dilemma of large companies. We didn't consider about IPR if the new technology is protected by patents. It's a problem of market entry barriers, which we think is another very important research question that we may study it further. At present, our assumption is that patents are provided by a third party, and the firms can compete fairly. Therefore, in the course of the game, the main issues that companies consider are relatively simple costs and benefits and competition issues. Our goal is to strip off some factors that affect corporate decision-making, such as corporate reputation, product patents, human resources, etc., to observe the dilemma in the corporate decision-making process from the most primitive point of view, so as to explain this unlikely but frequent phenomenon. The elasticities of demand also not considered in terms of formulating and predicting demand functions. New technologies often bring new demand and change the elasticity of demand in the original market. This is temporarily not considered by our model. On the one hand, it will greatly increase our solvable characteristics, and on the other hand, our problem will have a market invasion. This kind of new disruptive technology emerges more from the edge market, and many studies adopt the dual market hypothesis to conduct research, but this is another multi-technology hypothesis. The unidirectional vertical model has multiple ways of high-end and low-end intrusion. Here we use a horizontally differentiated model, because the competition between the two companies in the beginning is not very fierce. However, the two companies still have relative competition and have their own loyal customers. That is, the new quality dimension or the company has its own demand. More than which, we can avoid the condition that the company with the "low quality" new technology cannot surpass the market leader with the "higher quality" traditional technology. Considering this, we think that the competition we have provided is closer to reality.

\section{Appendix A.}

\section{Proof of Proposition 4.1}

In our hypothesis, the advantages and disadvantages of the old market can be expressed by $y$, so we can get the partial derivative of the new technology adoption time of the two monopoly firms: $\partial_{y} T 1 f=\frac{-2+\sqrt{2} \sqrt{\frac{K_{e}+K_{n}}{K_{e}}}}{2 k K_{n}}<0$ and $\partial_{y} T 1 f=-\frac{\sqrt{\frac{K_{e}+K_{n}}{K_{e}}}}{\sqrt{2} k K_{n}}<0$. Since the partial derivative is less than 0 , the advantages and disadvantages in the old market will promote the adoption of new technologies.

\section{Proof of Proposition 4.2}

If we compare the different adoption timing of the two firms, we can get that: $T 1 f-T 2 f=$ $\frac{\left(-1+\sqrt{2} \sqrt{\frac{K_{e}+K_{n}}{K_{e}}}\right) y}{k K_{n}}>0$. Thus, the conversion time of the advantage firm is late than the disadvantage firm. 


\section{Proof of Proposition 5.1}

To compare $T_{1}^{f}$ and $T_{2}^{f}$, we use $T_{1}^{f}$ minus $T_{2}^{f}$ and get $T_{1}^{f}-T_{2}^{f}=$ $\left(-2 y+\sqrt{2}\left(-\sqrt{\frac{\left(K_{e}+K_{n}\right)\left(9 K_{e}^{2}+18 K_{e} K-6 K_{e} y+y^{2}\right)}{K_{e}}}+\sqrt{\frac{\left(K_{e}+K_{n}\right)\left(9 K_{e}^{2}+y^{2}+6 K_{e}(3 K+y)\right.}{K_{e}}}\right)\right)$ $\frac{2 k K_{n}}{\left(-2 x^{2}\right.}$. Solving the inequality $T_{1}^{f}-T_{2}^{f}>0$, we can get that if $0<K<\frac{K_{e}^{2}+4 K_{e} K_{n}+4 K_{n}^{2}}{4\left(K_{e}+K_{n}\right)}$, or $\frac{K_{e}^{2}+4 K_{e} K_{n}+4 K_{n}^{2}}{4\left(K_{e}+K_{n}\right)}<K<\frac{K_{e}+2 K_{n}}{2} \& 0<y<$ $\frac{3 \sqrt{2} \sqrt{K_{e}} \sqrt{K_{e}+K_{n}} \sqrt{K_{e}-2 K+2 K_{n}}}{\sqrt{K_{e}+2 K_{n}}}$, then this inequality is established. Compare $T_{2}^{f}$ and $T_{1}^{l}$, we can get that $T_{2}^{f}<T_{1}^{l}$. Which means that the disadvantage firm in the old market will be the first mover at $T_{2}^{f}$, and the market leader will follow at $T_{1}^{l}$. And If $\frac{K_{e}^{2}+4 K_{e} K_{n}+4 K_{n}^{2}}{4\left(K_{e}+K_{n}\right)}<K<\frac{K_{e}+2 K_{n}}{2} \& \frac{3 \sqrt{2} \sqrt{K_{e}} \sqrt{K_{e}+K_{n}} \sqrt{K_{e}-2 K+2 K_{n}}}{\sqrt{K_{e}+2 K_{n}}}<y<3 K_{e}$, the inequality will be $T_{1}^{f}-T_{2}^{f}<0$, and $T_{2}^{l}$ doesn't exist. That means that the market leader will be the first mover, and the other firm won't follow. And if $K>\frac{K_{e}+2 K_{n}}{2}, 0<y<3 K_{e}$, the result won't change.

\section{Proof of Proposition 5.2}

As the competitor will adopt the new technology early than the market leader in the old market, then we can keep the condition we have derived in Proposition 5.1. To compare the market share, we let $x^{e n}$ to demonstrate the indifferent consumers when the Firm 1 chooses the established technology and Firm 2 chooses the disruptive technology. Let $x^{e n}=\frac{-c_{e}+c_{n}+K_{e}+2 K_{n}+b K_{n}-k K_{n} t}{3\left(K_{e}+K_{n}\right)}=1 / 2$, we have the time for the two firms to split the market share is $T_{\text {half }}=\frac{-2 c_{e}+2 c_{n}-K_{e}+K_{n}+2 b K_{n}}{2 k K_{n}}$. And $\partial_{t} x^{e n}<0$, which means that if $t>T_{\text {half }}$, the market share of the Firm 1 will be lower than Firm 2. Let $T_{2}^{f}-T_{\text {half }}=\frac{-3 K_{e}-3 K_{n}+\sqrt{2} \sqrt{\frac{\left(K_{e}+K_{n}\right)\left(9 K_{e}^{2}+18 K_{e} K-6 K_{e} y+y^{2}\right)}{K_{e}}}}{2 k K_{n}}$. We can get that when $K<\left(K_{e}+K_{n}\right) / 4$, and $0<y<\frac{3}{2}\left(2 K_{e}-\sqrt{2} \sqrt{K_{e}^{2}-4 K_{e} K+K_{e} K_{n}}\right)$, or if $\frac{K_{e}+K_{n}}{4}<$ $K<\frac{K_{e}^{2}+4 K_{e} K_{n}+4 K_{n}^{2}}{4\left(K_{e}+K_{n}\right)}$, we have $T_{2}^{f}>T_{\text {half }}$. Firm 1's market share will be lower than its competitor. When $\frac{3}{2}\left(2 K_{e}-\sqrt{2} \sqrt{K_{e}^{2}-4 K_{e} K+K_{e} K_{n}}\right)<y<3 K_{e}$, we have $T_{2}^{f}<T_{\text {half }}$. Firm 1 will have the higher market share in the market. However, if the new technology matures to the time the Firm 1 will adopt the technology, we have $T_{\text {half }}-T_{1}^{l}=-\frac{3\left(K_{e}+K_{n}-\sqrt{2} \sqrt{\left(K_{e}+K_{n}\right)\left(-2 K+K_{n}\right)}\right)}{2 k K_{n}}<0$. Then the market share of Firm 1 would still be below its competitor at that time.

We then compare the profits, let $W_{1}^{e n}=W_{2}^{e n}$. Express this indifference time as $T_{e n}$, we have $T_{e n}=$ $\frac{-2 c_{e}+2 c_{n}-K_{e}+3 K+K_{n}+2 b K_{n}}{2 k K_{n}}$. And we have $\partial_{t} W_{1}^{e n}<0, \partial_{t} W_{2}^{e n}>0$, which means when $t>T_{e n}$, the profits of Firm 1 will be lower than Firm 2. We have $T_{2}^{f}-T_{e n}=-\frac{3 K_{e}+3 K+3 K_{n}-\sqrt{2} \sqrt{\frac{\left(K_{e}+K_{n}\right)\left(9 K_{e}^{2}+18 K_{e} K-6 K_{e} y+y^{2}\right)}{K_{e}}}}{2 k K_{n}}$. We can get that, if $0<y<\min \left\{3 K_{e} \frac{3\left(2 K_{e}^{2}+2 K_{e} K n-\sqrt{2} \sqrt{K_{e}\left(K_{e}+K n\right)\left(K_{e}-K+K n\right)^{2}}\right)}{2\left(K_{e}+K n\right)}\right\}$, we have $T_{2}^{f}>T_{e n}$. As $-3 K_{e}+\frac{3\left(2 K_{e}^{2}+2 K_{e} K_{n}-\sqrt{2} \sqrt{K_{e}\left(K_{e}+K_{n}\right)\left(K_{e}-K+K_{n}\right)^{2}}\right)}{2\left(K_{e}+K_{n}\right)} \leq 0$, Then we have $0<y<$ $\frac{3\left(2 K_{e}^{2}+2 K_{e} K_{n}-\sqrt{2} \sqrt{K_{e}\left(K_{e}+K_{n}\right)\left(K_{e}-K+K_{n}\right)^{2}}\right)}{2\left(K_{e}+K_{n}\right)}$, the profit of the market leader will be lower than its competitor. And if $\frac{3\left(2 K_{e}^{2}+2 K_{e} K_{n}-\sqrt{2} \sqrt{K_{e}\left(K_{e}+K_{n}\right)\left(K_{e}-K+K_{n}\right)^{2}}\right)}{2\left(K_{e}+K_{n}\right)}<y<3 K_{e}$, we have $T_{2}^{f}<T_{e n}$, then the profit of the market leader will be still higher than the competitor. As $T_{e n}-T_{1}^{l}=-\frac{3\left(K_{e}-K+K_{n}-\sqrt{2} \sqrt{\left(K_{e}+K_{n}\right)\left(-2 K+K_{n}\right)}\right)}{2 k K_{n}}<0$. Then if the new technology can grow to the time that the Firm 1 adopt the new technology, the early adopter will be the market winner.

In total, when inferior firms in the old market first invest in new technologies, then let $y 3=\frac{3 \sqrt{2} \sqrt{K_{e}} \sqrt{K_{e}+K_{n}} \sqrt{K_{e}-2 K+2 K_{n}}}{\sqrt{K_{e}+2 K_{n}}}, \quad y 2=\frac{3}{2}\left(2 K_{e}-\sqrt{2} \sqrt{K_{e}^{2}-4 K_{e} K+K_{e} K_{n}}\right), \quad y 1=$ $\frac{3\left(2 K_{e}^{2}+2 K_{e} K_{n}-\sqrt{2} \sqrt{K_{e}\left(K_{e}+K_{n}\right)\left(K_{e}-K+K_{n}\right)^{2}}\right)}{2\left(K_{e}+K_{n}\right)} . K 1=\frac{K_{e}+K_{n}}{4}, K 2=\frac{K_{e}^{2}+4 K_{e} K_{n}+4 K_{n}^{2}}{4\left(K_{e}+K_{n}\right)}, K 3=\frac{K_{e}+2 K_{n}}{2}$. At the 
time that the inferior firms adopt the new technology, and the market came to the competition between technologies, we can get as the Figure 6 shows that: in Segment 1, the market share and the profit of the advantage firm will be lower than its competitor; in Segment 2, the market share of the advantage firm will be lower than its competitors, but its profit is still higher than its competitors; and in Segment 3, the market share and the profit of the advantage firm will still higher than its competitor, we call this dangerous area. For the reason that, if the new technology keeps its growth to $T_{1}^{l}$ that when the advantage firm adopts the new technology later, the inferior firm will be the new market leader in the new market.

\section{Proof of Proposition 5.3}

Compare $T_{i}^{f}$ and $T_{i}^{l}$, we can get that $T_{i}^{f}$ is always smaller than $T_{i}^{l}$. $T_{i}^{f}$ is the optimal time for firm $i$ to adopt the new technology when there is no first mover, if other firm gets the new technology in advance, then the optimal time will be $T_{i}^{l}$. Description of the relationship between the two time show that the late mover at $T_{i}^{f}$ will be delayed to $T_{i}^{f}$ as the competition effect.

\section{Proof of Proposition 6.1}

We can get that $T 1-T 2=-\frac{9 K\left(K_{e}+K_{n}\right) y}{k K_{n}\left(3 K_{e}+3 K_{n}-y\right)\left(3 K_{e}+3 K_{n}+y\right)}<0$. Which means the market leader will preempt earlier than the incumbent competitor.

\section{Proof of Proposition 6.2}

We can get that $T 1-T 3=\frac{y\left(3 K_{e}+3 K_{n}-3 K+y\right)}{2 K K_{n}\left(3 K_{e}+3 K_{n}+y\right)}>0$. Then the proposition is proved.

\section{Proof of Proposition 6.3}

Let $W_{1}^{n e}=\frac{\left(c_{e}-c_{n}+2 K_{e}+K_{n}-b K_{n}+k K_{n} t+y\right)^{2}}{9\left(K_{e}+K_{n}\right)}-K, W_{2}^{n e}=\frac{\left(-c_{e}+c_{n}+K_{e}+2 K_{n}+b K_{n}-k K_{n} t-y\right)^{2}}{9\left(K_{e}+K_{n}\right)}$. And $W_{1}^{n e}=W_{2}^{n e}$, we get $T^{*}=\frac{-2 c_{e}+2 c_{n}-K_{e}+3 K+K_{n}+2 b K_{n}-2 y}{2 k K_{n}}$. This is the time that, even the market leader preempts the adoption, the profit of the market leader is still higher than its incumbent competitors if the adoption time is later than $T^{*}$. And we can get $T^{*}-T 3=\frac{-6 \sqrt{\frac{k^{2} K K_{n}^{2}}{K_{e}+K_{n}}}\left(K_{e}+K_{n}\right)+k K_{n}\left(3 K_{e}+3 K+3 K_{n}-2 y\right)}{2 k^{2} K_{n}^{2}}>0$. Which means if the market leader preempts the time earlier than the entrant (T3) to deter the entrance. The profits of the market leader will be lower than its current competitor. Then the proposition is proved.

\section{Proof of Proposition 6.4}

To avoid choosing the wrong technology path, the earliest time that the market leader can preempt the adoption is $T^{*}$. As shown in Proposition 6.3, the market leader can keep the advantage position while choosing the new disruptive technology. However, if there is another firm that have chosen the disruptive technology, the adoption time cannot be later than the social time $T^{\#}$, as it is also the time that the market leader loses the advantage position to the disruptive technology while keeping the old technology. As the preemption strategy is to trade the current profit for future market leader, then delay the adoption can reduce the losses. But this delay must avoid early adoption by stronger incumbent competitors as shown in Figure 8 . Then we have Proposition 6.4 proved.

Acknowledgements. This work was supported by National Natural Science Foundation of China (71672140/G021001). The authors have no conflicts of interest to declare that are relevant to the content of this article.

\section{REFERENCES}

[1] Accenture, New "disruptability index" busts widespread myth that industry disruption is a random occurrence. Available at: https://newsroom.accenture.com/news/nearly-two-thirds-of-large-companies-globally-face-high-levels-ofindustry-disruption-accenture-study-finds.htm (Access on February 26, 2018).

[2] R. Adner and R. Kapoor, Value creation in innovation ecosystems: How the structure of technological interdependence affects firm performance in new technology generations. Strategic Manage. J. 31 (2010) 306-333.

[3] R. Adner and R. Kapoor, Right tech, wrong time. Harvard Bus. Rev. 94 (2016) 60-67. 
[4] R. Adner and P. Zemsky, Disruptive technologies and the emergence of competition. RAND J. Econ. 36 (2005) $229-254$.

[5] M.-L. Allain, E. Henry and M. Kyle, Competition and the efficiency of markets for technology. Manage. Sci. 62 (2016) 1000-1019.

[6] E.J. Anderson and S.J. Sunny Yang, The timing of capacity investment with lead times: When do firms act in unison? Prod. Oper. Manage. 24 (2015) 21-41.

[7] S. Ansari, R. Garud and A. Kumaraswamy, The disruptor's dilemma: TiVo and the US television ecosystem. Strategic Manage. J. 37 (2016) 1829-1853.

[8] A. Arora, A. Fosfuri and T. Rønde, Managing licensing in a market for technology. Manage. Sci. 59 (2013) $1092-1106$.

[9] F.M. Bass, A new product growth for model consumer durables. Manage. Sci. 15 (1969) 215-227.

[10] S.R. Bhaskaran and K. Ramachandran, Managing technology selection and development risk in competitive environments. Prod. Oper. Manage. 20 (2011) 541-555.

[11] I. Bildosola, G. Garechana, E. Zarrabeitia and E. Cilleruelo, Characterization of strategic emerging technologies: the case of big data. Cent. Eur. J. Oper. Res. 28 (2020) 45-60.

[12] Boston Consulting Group, Flipping the odds of digital transformation success. Available at: https://www.bcg.com/zh-cn/ publications/2020/increasing-odds-of-success-in-digital-transformation (Access on October 29, 2020).

[13] M.-J. Chen and D. Miller, Competitive dynamics: themes, trends, and a prospective research platform. Acad. Manage. Ann. 6 (2012) 135-210.

[14] Y. Chen and Ö. Turut, Context-dependent preferences and innovation strategy. Manage. Sci. 59 (2013) $2747-2765$.

[15] C. Chen, J. Zhang and R.-S. Guo, The D-Day, V-Day, and bleak days of a disruptive technology: a new model for ex-ante evaluation of the timing of technology disruption. Eur. J. Oper. Res. 251 (2016) 562-574.

[16] H. Chen, Y.J. Hu and M.D. Smith, The impact of E-book distribution on print sales: analysis of a natural experiment. Manage. Sci. 65 (2019) 19-31.

[17] C.M. Christensen, The Innovator's Dilemma. Harvard Business School Press. Boston, MA (1997).

[18] C.M. Christensen, R. McDonald, E.J. Altman and J.E. Palmer, Disruptive innovation: an intellectual history and directions for future research. J. Manage. Stud. 55 (2018) 1043-1078.

[19] M.A. Cohen, J. Eliasberg and T.-H. Ho, New product development: the performance and time-to-market tradeoff. Manage. Sci. 42 (1996) 173-186.

[20] K.R. Conner, Obtaining strategic advantage from being imitated: When can encouraging "clones" pay? Manage. Sci. 41 (1995) 209-225.

[21] J.A. Cookson, Anticipated entry and entry deterrence: evidence from the American casino industry. Manage. Sci. 64 (2018) 2325-2344.

[22] F. Crowley, Product and service innovation and discontinuation in manufacturing and service firms in Europe. Eur. J. Innov. Manage. 20 (2017) 250-268.

[23] R.A. D'Aveni, G.B. Dagnino and K.G. Smith, The age of temporary advantage. Strategic Manage. J. 31 (2010) $1371-1385$.

[24] G.B. Dagnino, P.M. Picone and G. Ferrigno, Temporary competitive advantage: a state-of-the-art literature review and research directions. Int. J. Manage. Rev. 23 (2021) 85-115.

[25] M. Ernzer and W. Wimmer, From environmental assessment results to design for environment product changes: an evaluation of quantitative and qualitative methods. J. Eng. Des. 13 (2002) 233-242.

[26] R.N. Foster, Working the S-curve: assessing technological threats. Res. Manage. 29 (1986) 17-20.

[27] J. Frizzo-Barker, P.A. Chow-White, P.R. Adams, J. Mentanko, D. Ha and S. Green, Blockchain as a disruptive technology for business: a systematic review. Int. J. Inf. Manage. 51 (2020) 102029.

[28] J.J. Gabszewicz and J.-F. Thisse, Spatial Competition and the Location of Firms. Harwood Academic Publishers Chur, Switzerland (1986).

[29] C. Giachetti, J. Lampel and S.L. Pira, Red queen competitive imitation in the UK mobile phone industry. Acad. Manage. J. 60 (2017) 1882-1914.

[30] G.M. Grossman and E. Helpman, Quality ladders in the theory of growth. Rev. Econ. Stud. 58 (1991) 43-61.

[31] D.A. Guttentag and S.L. Smith, Assessing Airbnb as a disruptive innovation relative to hotels: substitution and comparative performance expectations. Int. J. Hospitality Manage. 64 (2017) 1-10.

[32] A. Ha, X. Long and J. Nasiry, Quality in supply chain encroachment. Manuf. Serv. Oper. Manage. 18 (2016) $280-298$.

[33] A. Hagiu and E.J. Altman, Finding the platform in your product. Harvard Bus. Rev. 95 (2017) 94-100.

[34] R. Hamzeh and X. Xu, Technology selection methods and applications in manufacturing: a review from 1990 to 2017. Comput. Ind. Eng. 138 (2019) 106123.

[35] X. Huang and G. Sošić, Analysis of industry equilibria in models with sustaining and disruptive technology. Eur. J. Oper. Res. 207 (2010) 238-248.

[36] N.F. Huberts, H. Dawid, K.J. Huisman and P.M. Kort, Entry deterrence by timing rather than overinvestment in a strategic real options framework. Eur. J. Oper. Res. 274 (2019) 165-185.

[37] R. Iyengar, C. Van den Bulte and T.W. Valente, Opinion leadership and social contagion in new product diffusion. Market. Sci. 30 (2011) 195-212.

[38] S. Jain and K. Ramdas, Up or out - or stay put? Product positioning in an evolving technology environment. Prod. Oper. Manage. 14 (2005) 362-376. 
[39] M. Janssen, V. Weerakkody, E. Ismagilova, U. Sivarajah and Z. Irani, A framework for analysing blockchain technology adoption: integrating institutional, market and technical factors. Int. J. Inf. Manage. 50 (2020) 302-309.

[40] K. Jerath, S.-H. Kim and R. Swinney, Product quality in a distribution channel with inventory risk. Market. Sci. 36 (2017) $747-761$.

[41] Z. Jiang, X.S. Qu and D.C. Jain, Optimal market entry timing for successive generations of technological innovations. MIS Q. Forthcoming (2018).

[42] R.A. Kerin, P.R. Varadarajan and R.A. Peterson, First-mover advantage: a synthesis, conceptual framework, and research propositions. J. Market. 56 (1992) 33-52.

[43] S.N. Kirshner, Y. Levin and M. Nediak, Product upgrades with stochastic technology advancement, product failure, and brand commitment. Prod. Oper. Manage. 26 (2017) 742-756.

[44] T. Klastorin and W. Tsai, New product introduction: timing, design, and pricing. Manuf. Serv. Oper. Manage. 6 (2004) 302-320.

[45] T. Knudsen, D.A. Levinthal and S.G. Winter, Hidden but in plain sight: the role of scale adjustment in industry dynamics. Strategic Manage. J. 35 (2014) 1569-1584.

[46] V. Krishnan and W. Zhu, Designing a family of development-intensive products. Manage. Sci. 52 (2006) $813-825$.

[47] Y. Kwark, J. Chen and S. Raghunathan, User-generated content and competing firms' product design. Manage. Sci. 64 (2018) 4608-4628.

[48] P. Lacourbe, C.H. Loch and S. Kavadias, Product positioning in a two-dimensional market space. Prod. Oper. Manage. 18 (2009) 315-332.

[49] D.O. Lauga and E. Ofek, Market research and innovation strategy in a duopoly. Market. Sci. 28 (2009) $373-396$.

[50] D. Majumdar, P.K. Banerji and S. Chakrabarti, Disruptive technology and disruptive innovation: ignore at your peril! Technol. Anal. Strategic Manage. 30 (2018) 1247-1255.

[51] M. Marx, J.S. Gans and D.H. Hsu, Dynamic commercialization strategies for disruptive technologies: evidence from the speech recognition industry. Manage. Sci. 60 (2014) 3103-3123.

[52] D.B. Montgomery, M.C. Moore and J.E. Urbany, Reasoning about competitive reactions: evidence from executives. Market. Sci. 24 (2005) 138-149.

[53] D. Nagy, J. Schuessler and A. Dubinsky, Defining and identifying disruptive innovations. Ind. Market. Manage. 57 (2016) 119-126.

[54] G.F. Özkan-Seely, Strategies for environmental and traditional quality efforts during new product development: balancing complementarity and conflict. Qual. Manage. J. 21 (2014) 23-35.

[55] A.K. Parlaktürk, The value of product variety when selling to strategic consumers. Manuf. Serv. Oper. Manage. 14 (2012) 371-385.

[56] R. Peres, E. Muller and V. Mahajan, Innovation diffusion and new product growth models: a critical review and research directions. Int. J. Res. Market. 27 (2010) 91-106.

[57] N. Petzold, L. Landinez and T. Baaken, Disruptive innovation from a process view: a systematic literature review. Creativity Innov. Manage. 28 (2019) 157-174.

[58] S. Rakthin, R.J. Calantone and J.F. Wang, Managing market intelligence: the comparative role of absorptive capacity and market orientation. J. Bus. Res. 69 (2016) 5569-5577.

[59] R.C. Seamans, Threat of entry, asymmetric information, and pricing. Strategic Manage. J. 34 (2013) $426-444$.

[60] S. Si, S.A. Zahra, X. Wu and D.J.-F. Jeng, Disruptive innovation and entrepreneurship in emerging economics. J. Eng. Technol. Manage. 58 (2020) 101601.

[61] A. Steiber, S. Alänge, S. Ghosh and D. Goncalves, Digital transformation of industrial firms: an innovation diffusion perspective. Eur. J. Innov. Manage. 24 (2020) 799-819.

[62] R. Swinney, G.P. Cachon and S. Netessine, Capacity investment timing by start-ups and established firms in new markets. Manage. Sci. 57 (2011) 763-777.

[63] B. Uzunca, A competence-based view of industry evolution: the impact of submarket convergence on incumbent-entrant dynamics. Acad. Manage. J. 61 (2018) 738-768.

[64] J. Woo and C.L. Magee, Relationship between technological improvement and innovation diffusion: an empirical test. Technol. Anal. Strategic Manage. (2021) 1-16.

[65] C.-H. Wu, Price competition and technology licensing in a dynamic duopoly. Eur. J. Oper. Res. 267 (2018) $570-584$.

[66] C.-H. Wu and J.-Y. Lai, Dynamic pricing and competitive time-to-market strategy of new product launch under a multistage duopoly. Eur. J. Oper. Res 277 (2019) 138-152.

[67] L. Yang, A. Jiang and J. Zhang, Optimal timing of big data application in a two-period decision model with new product sales. Comput. Ind. Eng. 160 (2021) 107550.

[68] A. Yenipazarli, Incentives for environmental research and development: consumer preferences, competitive pressure and emissions taxation. Eur. J. Oper. Res. 276 (2019) 757-769.

[69] J. Zhan, T. Xu, X. Xu and Y. Jin, Trade credit or vertical merger strategy for financial constrained retailer in a supply chain with asymmetric competing retailers. RAIRO-Oper. Res. 55 (2021) 1617-1641.

[70] F. Zhu and N. Furr, Products to platforms: making the leap. Harvard Bus. Rev. 94 (2016) 72-78. 
[71] X. Zhu and G. Wu, Green product diffusion: the impacts of asymmetric retailers' strategic product decisions. RAIRO-Oper. Res. 55 (2021) 1459-1486.

\section{Subscribe to Open (S2O) A fair and sustainable open access model}

This journal is currently published in open access under a Subscribe-to-Open model (S2O). S2O is a transformative model that aims to move subscription journals to open access. Open access is the free, immediate, online availability of research articles combined with the rights to use these articles fully in the digital environment. We are thankful to our subscribers and sponsors for making it possible to publish this journal in open access, free of charge for authors.

\section{Please help to maintain this journal in open access!}

Check that your library subscribes to the journal, or make a personal donation to the S2O programme, by contacting subscribers@edpsciences.org

More information, including a list of sponsors and a financial transparency report, available at: https://www. edpsciences.org/en/maths-s2o-programme 